\title{
Acetylcholine release in rat frontal and somatosensory cortex is enhanced during tactile discrimination learning
}

\author{
ALLEN E. BUTT \\ Université de Montréal, Montreal, Quebec, Canada \\ GUY TESTYLIER \\ Centre de Recherches du Service de Santé des Armées, Grenoble, France \\ and \\ ROBERT W. DYKES \\ Université de Montréal, Montreal, Quebec, Canada
}

\begin{abstract}
We examined acetylcholine (ACh) release in the frontal cortex and in the vibrissae representation in the somatosensory cortex in rats during the acquisition of a tactile discrimination or during nondiscrimination control procedures. Microdialysis samples were collected for $1 \mathrm{~h}$ in the home cage and then for the duration of 30 discrimination or control trials, across 5 consecutive days. Both groups showed significant testing-induced increases in ACh release in both cortical sites. However, rats in the discrimination training group showed even greater testing-induced increases in ACh release in the somatosensory cortex and had a proportionately greater increase in somatosensory cortex than in frontal cortex, relative to controls. The results suggest that, in addition to the widespread enhancement of $\mathrm{ACh}$ release associated with appetitive conditioning procedures in general, tactile discrimination training causes a regionally specific enhancement in ACh release in the somatosensory cortex that is related to discrimination performance.
\end{abstract}

Acetylcholine $(\mathrm{ACh})$ is released in rat neocortex in response to a variety of behavioral and environmental conditions, including wakefulness (Jiménez-Capdeville \& Dykes, 1993; Kametani \& Kawamura, 1991), motor activity (Day, Damsma, \& Fibiger, 1991), and restraintor handling-induced stress (Rosenblad \& Nilsson, 1993). Cortical ACh release is also induced by exposure to darkness (Moore, Sarter, \& Bruno, 1992) and by auditory, visual, or somatosensory stimulation (Inglis \& Fibiger, 1995; Kurosawa, Sato, \& Sato, 1992). In addition to these findings, which demonstrate differences in $\mathrm{ACh}$ release related to different states of arousal, evidence suggests that $\mathrm{ACh}$ release in the neocortex may also be modified by associative conditioning (see Acquas, Wilson, \& Fibiger, 1996; Inglis, Day, \& Fibiger, 1994; Moore, Sarter,

\footnotetext{
A.E.B. was supported by the Programme Québécois Bourses de Excellence (Quebec, Canada), and R.W.D. was supported by the Medical Research Council of Canada and by the Scottish Rite Foundation. Portions of this experiment were previously presented at the Society for Neuroscience 25th Annual Meeting (Society for Neuroscience Abstracts, 21, 1448). The authors gratefully acknowledge Rima Chibib and Tuyet Phan Trieu for assistance in data collection, Julia Martinson for assistance in data analysis, Giovanni Filosi for providing the illustrations, and Brent Cooper for valuable discussion on the experimental design. Correspondence should be addressed to A. E. Butt, Departément de Physiologie, Université de Montréal, C.P. 6128, Succursale Centre-ville, Montreal, PQ, Canada H3C 3J7 (e-mail: butta@ ere.umontreal.ca).
}

\& Bruno, 1993; Rasmusson \& Szerb, 1976; Sarter \& Bruno, 1994). The purpose of the present experiment was to measure $\mathrm{ACh}$ release in the rat frontal and somatosensory cortices during acquisition in a tactile discrimination paradigm in order to increase our understanding of cortical cholinergic involvement in associative learning and memory.

Using in vivo microdialysis and biochemical detection techniques, others have shown that $\mathrm{ACh}$ release in frontal cortex is influenced by behavioral conditioning (Acquas et al., 1996; Inglis et al., 1994; Moore et al., 1993; Sarter \& Bruno, 1994; also see Rasmusson \& Szerb, 1976). For example, Inglis et al. (1994) found that $\mathrm{ACh}$ release in rat frontal cortex is enhanced by appetitive conditioning. Their procedures involved placing rats in a two-chambered apparatus where, after remaining for $20 \mathrm{~min}$ in one side, rats were allowed access to food reinforcement for an additional $20 \mathrm{~min}$ on the other side of the apparatus. Compared with those of naive rats, $\mathrm{ACh}$ levels in the frontal cortex of trained rats were significantly greater both during the anticipatory phase, when the rat was kept in the chamber adjacent to the one containing the reinforcer, and during the actual consumption of the reinforcer in the second chamber (Inglis et al., 1994). Similarly, Moore et al. (1993) showed that signaling the availability of food reinforcement with a conditioned visual stimulus (i.e., onset of darkness) led to an enhancement of ACh release in frontal cortex of rats; this enhancement exceeded 
that associated with the onset of darkness alone (cf. Moore et al., 1992).

Recently, Fibiger and colleagues (Acquas et al., 1996) provided evidence that basal forebrain cholinergic neurons in the medial septum and nucleus basalis magnocellularis (NBM) projecting to neocortex and hippocampus, respectively, are involved specifically in arousal or attentional processes during conditioning. These researchers subjected three groups of rats to different conditions involving the presentation of a light and a tone. The first group, the "habituation" group, was repeatedly exposed to the light and tone prior to microdialysis testing. The second group, the "novel-stimuli" group, was not exposed to the light and tone until the day of microdialysis testing, although they were previously exposed to the testing environment. The third group, the "conditioned-fear" group, was trained in a classical conditioning paradigm where the light and tone were paired with footshock many times prior to microdialysis testing. Results showed that $\mathrm{ACh}$ release in the frontal cortex and hippocampus was significantly increased during exposure to the light and tone if these stimuli were novel (novel group) or if they had been previously paired with footshock (conditioned-fear group), but not if they were extensively preexposed in the absence of footshock (habituation group). These findings demonstrate that the presentation of classically conditioned or novel stimuli can increase both cortical and hippocampal ACh release (Acquas et al., 1996).

Additional evidence for cholinergic involvement in behavioral conditioning comes from electrophysiological studies showing enhanced activity in the cell bodies of the NBM or its cortical targets in response to the presentation of specific sensory cues predicting either reinforcing or aversive events (Maho, Hars, Edeline, \& Hennevin, 1995; Pirch, Rigdon, Rucker, \& Turco, 1990; Richardson \& DeLong, 1990, 1991; Wilson \& Rolls, 1990). For example, in addition to responding to the presentation of reinforcing (e.g., fruit juice) or aversive (e.g., saline) unconditioned stimuli, NBM neurons in monkeys respond differentially upon the presentation of discriminative visual (Richardson \& DeLong, 1990, 1991; Wilson \& Rolls, 1990) or auditory (Wilson \& Rolls, 1990) stimuli. Cells in the NBM in rats similarly exhibit differential responding upon the presentation of discriminative visual (Pirch, 1993; Pirch et al., 1990) or auditory (Maho et al., 1995; Rigdon \& Pirch, 1986) stimuli.

In addition to these biochemical and electrophysiological findings, results from behavioral studies involving neurotoxic lesions of the NBM suggest a critical role of $\mathrm{ACh}$ in learning and memory. Damage to the cell bodies of the NBM results in the widespread deafferentation of their cortical targets and leads to a wide variety of behavioral impairments (for reviews see Dekker, Connor, \& Thal, 1991; Fibiger, 1991; Kesner, 1988; Olton, 1990; Olton \& Wenk, 1987). The behavioral consequences of NBM lesions have been variously described as impaired working memory (e.g., Beninger, Wirsching, Jhamandas, Boegman, \& El Defrawy, 1986; Hepler, Olton, Wenk, \&
Coyle, 1985; Knowlton, Wenk, Olton, \& Coyle, 1985), impaired memory retention (e.g., Miyamoto, Kato, Narumi, \& Nagaoka, 1987; Ueki \& Miyoshi, 1989), a failure of response inhibition resulting in behavioral perseveration (e.g., Dubois, Mayo, Agid, LeMoal, \& Simon, 1985; Roberts et al., 1990; Santucci \& Haroutunian, 1989), and as an impairment in attentional processes including selective attention (e.g., Butt \& Hodge, 1995; Chiba, Bucci, Holland, \& Gallagher, 1995; Muir, Page, Sirinathsinghji, Robbins, \& Everitt, 1993; Pang, Williams, Egeth, \& Olton, 1993; Robbins et al., 1989). Despite these differing approaches to defining the processes that are disturbed by NBM lesions, the abundance of literature showing NBM lesion-induced behavioral impairments suggests that cortical cholinergic innervation from the NBM plays an especially important role in learning and memory (but see Dunnett, Everitt, \& Robbins, 1991; Markowska, Wenk, \& Olton, 1990; Riekkinen, Riekkinen, \& Riekkinen, 1991).

In the present experiment, we used in vivo microdialysis techniques to measure $\mathrm{ACh}$ release in the frontal cortex and in the vibrissae representation of the somatosensory cortex in rats during a baseline period in the home cage and during tactile discrimination training or control procedures. Rats in the discrimination training group had to discriminate between two different tactile stimuli for reinforcement, whereas controls were exposed to the same stimuli and were reinforced but were not required to learn the discrimination. We measured $\mathrm{ACh}$ release in the frontal cortex to determine whether the conditioningdependent enhancement of ACh release reported by others (Inglis et al., 1994; Moore et al., 1993; Rasmusson \& Szerb, 1976) would also occur during tactile discrimination learning. Additionally, because others have shown that associative conditioning can induce long-lasting changes in the response properties of somatosensory cortical neurons (e.g., Delacour, Houcine, \& Costa, 1990a, 1990b; Delacour, Houcine, \& Talbi, 1987; Diamond, Armstrong-James, \& Ebner, 1993; Recanzone, Jenkins, Hradek, \& Merzenich, 1992), and because the cholinergically innervated vibrissae barrel field in the somatosensory cortex is involved in vibrissae-mediated tactile learning (see Guic-Robles, Jenkins, \& Bravo, 1992; Hutson \& Masterton, 1986; Jacobs \& Juliano, 1995; Kossut, 1992; Wozniak, Stewart, Finger, Olney, \& Cozzari, 1989), we chose to study ACh release in this region during the acquisition of a tactile discrimination task.

On the basis of reports of enhanced ACh release in the frontal cortex of appetitively conditioned rats (e.g., Inglis et al., 1994; Moore et al., 1993), we hypothesized that ACh release in the frontal cortex of both the discrimination training group and the control group would be greater during behavioral testing than during baseline measures in the home cage; such an increase would be expected because both groups were trained to receive reinforcement in the testing apparatus. Additionally, on the basis of previous research demonstrating the involvement of the cholinergically innervated barrel field cortex in tactile discrimination learning (Guic-Robles et al., 1992; Hut- 
son \& Masterton, 1986; Jacobs \& Juliano, 1995; Kossut, 1992; Wozniak et al., 1989), we hypothesized that rats learning to discriminate between different textures would show greater levels of $\mathrm{ACh}$ release than would controls that were exposed to the same textures and reinforcers but that did not have to learn the discrimination. The increase in demands on attention to the tactile stimuli in the discrimination training group was expected to cause an increase in somatosensory cortical processing and a concomitant increase in ACh efflux.

\section{METHOD}

\begin{abstract}
Animals
Seven male Sprague-Dawley rats (Charles River, St. Constant, Quebec), each weighing approximately $350 \mathrm{~g}$, were housed individually under a reversed 12 -h light cycle (lights on at $1800 \mathrm{~h}$ ) for a period of 2 weeks prior to surgical and behavioral procedures. The rats were allowed free access to food and water and were handled daily by the experimenter during this time. Beginning 1 week postoperatively, the rats were placed on a restricted food schedule where their weights were reduced to and maintained at approximately $85 \%$ of their normal body weights. During habituation, pretraining, and discrimination training or control testing, the rats were fed at the end of each day, upon completion of behavioral procedures; all behavioral testing was conducted between 1200 and $1600 \mathrm{~h}$, with individual discrimination training and control rats being tested alternately. Water was freely available throughout the experiment except during daily baseline and testing procedures (total time approximately $2 \mathrm{~h} /$ day). Upon completion of habituation and pretraining procedures (see below), the rats were randomly assigned to the discrimination training $(n=4)$ or control $(n=3)$ groups.
\end{abstract}

\section{Surgery}

The rats were anesthetized with sodium pentobarbital $(40 \mathrm{mg} /$ kg i.p.; Sigma, St. Louis, MO) and placed in a stereotaxic frame (Kopf Stereotaxic Instruments, Tujunga, CA), with the incisor bar set at $3.0 \mathrm{~mm}$ below the interaural line. The scalp was incised and reflected from the top of the skull, where a rectangular craniotomy was drilled over the left hemisphere extending from $3.3 \mathrm{~mm}$ anterior to bregma to $4.7 \mathrm{~mm}$ posterior to bregma and from 0.5 $4.5 \mathrm{~mm}$ lateral to midline.

An assembly composed of two intracerebral microdialysis probe guides fitted with dummy cannulae (Model CMA-12, Bioanalytical Systems Inc., West Lafayette, IN) was positioned above the exposed dura at a $45^{\circ}$ angle, extending away from midline. The tip of the anterior guide was positioned $1.4 \mathrm{~mm}$ anterior to bregma, and the tip of the posterior guide was positioned $2.6 \mathrm{~mm}$ posterior to bregma; both guide tips were positioned $1.5 \mathrm{~mm}$ lateral to midline at the level of the dura. Small incisions were made in the dura to allow passage of the probe guides. The probe guides were then lowered at a $45^{\circ}$ angle $2 \mathrm{~mm}$ below dura, moving ventrally and laterally into the brain. The anterior guide thus came to rest in the frontal cortex (see Paxinos \& Watson, 1986), and the posterior guide came to rest in the vibrissae region of the somatosensory cortex, as defined by Chapin and Lin (1984). The rat barrel field typically extends from $\sim 0.5-4.0 \mathrm{~mm}$ posterior to bregma and from $\sim 4.4$ $7.0 \mathrm{~mm}$ lateral to midline (see Chapin \& Lin, 1984); the probe guides were positioned such that when the microdialysis probes were inserted, they would extend ventrolaterally through the lower cortical layers in the central portion of the barrel field, $\sim 4.0$ $7.0 \mathrm{~mm}$ lateral to midline.

The dura surrounding the probe guides was covered with gelfoam, and the probe guide assembly was secured to the surface of the skull by embedding the lower half of each guide housing in a mound of dental acrylic; the dental acrylic was anchored to the skull via three small, stainless steel screws positioned along the edges of the craniotomy. A small eyescrew, later used to connect the rat to a tether during testing, was also embedded in the mound of dental acrylic. The incision was cleaned and sutured, and the rats were administered an antibiotic $(2.5 \mathrm{mg} / \mathrm{kg}$ i.m. enroflaxin; Miles Canada Inc., Etobicoke, Ontario) to avoid possible infection. The rats were allowed 1 week to recover from surgery prior to initiating food deprivation and subsequent behavioral training.

\section{Apparatus}

Baseline ACh release measures were collected while the rats remained in the home cage, an opaque plastic box $(20 \times 18 \times$ $40 \mathrm{~cm})$ filled with a layer $(2 \mathrm{~cm})$ of cedar chip bedding. During the collection of baseline data, the standard wire lid and water bottle were removed from the home cage and replaced with a wire lid that was modified to allow free passage of the microdialysis tubing and the tether connected to the assembly on the rat's head; food and water were not available during baseline measures.

Behavioral testing and microdialysis sampling was conducted in a three-chambered apparatus made of laminated wood with a clear plastic lid and plastic fittings (see Figure 1). The apparatus (outside dimensions, $26 \times 36 \times 40 \mathrm{~cm}$ ) consisted of a common starting location $(26 \times 36 \times 14 \mathrm{~cm})$ connected to two response chambers $(26 \times 18 \times 26 \mathrm{~cm})$. The response chambers were separated from the starting location by a pair of retractable plastic doors. The lower edges of these doors were elevated from the chamber floor by $1 \mathrm{~cm}$ to allow the rat's tail to extend into the adjacent chamber without being injured when the doors closed. Narrow slots $(5 \mathrm{~mm}$ high) were positioned along the rear wall of the response chambers; these slots allowed the experimenter to remove or insert the tactile discriminanda from outside the apparatus. Small holes were positioned along the outer wall at the end of each response chamber; these holes, which served as food magazines, allowed the experimenter to deliver individual pieces of cereal (Cheerios) to the rat from outside the apparatus. The entire apparatus was covered with a clear plastic lid constructed in two pieces; one piece covered the two response chambers, and the other piece covered the starting location. Centered along the adjoining edges of each piece of the lid were two semicircular openings; these openings formed a hole through which the microdialysis tubing and rat tether could pass. Suspended above each response chamber were clear plastic panels that could be moved from the rear wall of the chamber toward the common starting location along narrow slots in the lid; these panels allowed the experimenter to force the rat out of either response chamber and into the common starting location at the end of a trial.

The tactile discriminanda were $2-\mathrm{mm}$-thick rectangular plates $(26 \times 18 \times 26 \mathrm{~cm})$ made of textured plastic that covered the floor of each response chamber. Half of the plates were textured with an uneven, "crystalline" surface, composed of a random pattern of ridges and valleys; the other half were textured with an even, "toothed" surface, composed of a regular pattern of dimples and peaks. A sufficient number of these plates were constructed so that a clean set of plates could be used on every trial in the testing session.

\section{Habituation and Pretraining}

Beginning 10 days postoperatively, food-deprived rats were habituated to the testing apparatus. The rats were first placed individually in the testing apparatus, with several pieces of cereal scattered on the floor in both response chambers. The rats were allowed to explore the apparatus and consume the available reinforcers for $1 \mathrm{~h}$ each day for 3 consecutive days. The rats were then pretrained to earn food reinforcement by entering the response chambers. The rats were connected to the tether suspended over the apparatus and placed in the starting location of the apparatus. The doors to the response chambers were then opened, and the rat was allowed access to both response chambers. When the rat crossed into either of the two chambers with all four feet, the doors were closed behind the 


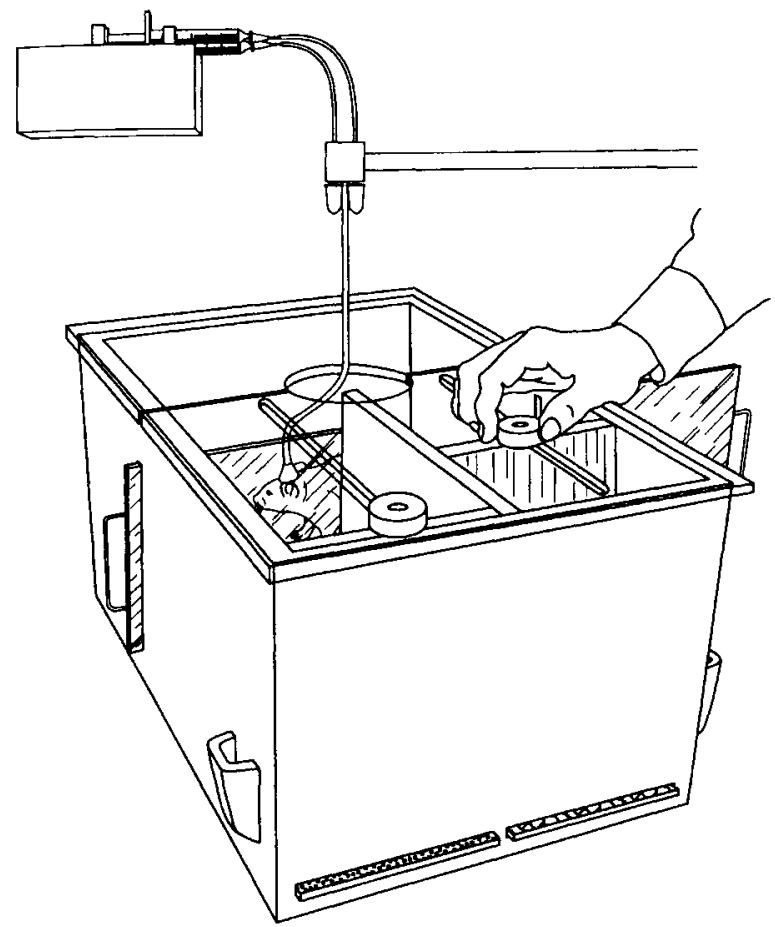

Figure 1. Testing apparatus and experimental setup for microdialysis during discrimination-training and control procedures. The rat is shown here being forced from the response chamber on the right into the common starting location of the apparatus. The experimenter forces the rat out of the response chamber by slowly moving a suspended panel toward the entrance to the chamber along a narrow slot cut in the lid. The door to the response chamber on the right is in the open position, allowing the rat to exit, whereas the door to the response chamber on the left is in the closed position. The ends of the textured plates lying on the floors of each response chamber are visible at the front of the apparatus, where they are inserted or removed by the experimenter between trials. Food magazines are located on the sides of the apparatus, at the rear of each response chamber. The entire apparatus is covered by a two-piece, clear plastic lid with a hole in the center to allow passage of the rat tether and plastic microtubing attached to the microdialysis probes. A microinfusion pump located near the apparatus contains two syringes connected via microtubing to a dual-channel swivel suspended over the apparatus by a horizontal arm. Microtubing leads from the dual-channel swivel through the hole in the lid to the microdialysis probes implanted in the rat brain and, finally, from the microdialysis probes to a pair of sample collection vials located below the dual-channel swivel.

rat, and a food reinforcer was delivered at the rear of the chamber. The rats were reinforced regardless of which chamber they selected. After the rat consumed the reinforcer, the chamber door was opened and the rat was allowed to return to the starting location; if the rat did not leave the response chamber within $20 \mathrm{sec}$, the experimenter would gently force the rat out of the chamber by slowly moving the suspended panel positioned at the rear of the chamber toward the starting location. The rat was kept in the starting location for another $20 \mathrm{sec}$ prior to initiating the next pretraining trial. All rats received 50 trials (approximately $1 \mathrm{~h}$ ) of this pretraining on each of 3 consecutive days. Upon completion of pretraining, the rats would reliably enter both chambers, quickly consume the reinforcer, and exit either as soon as the chamber door was opened or as soon as the rear panel was moved toward the starting location.

\section{Discrimination-Training Procedures}

Discrimination-training procedures began 17 days postoperatively and $24 \mathrm{~h}$ following the insertion of the microdialysis probes (see below). The rats in the discrimination-training group received 30 discrimination trials per day for 5 consecutive days, with the number of correct responses being calculated in terms of percent correct for each rat on each day. The toothed surface was designated as correct for half of the rats, and the crystalline surface was designated as correct for the other half of the rats in the discriminationtraining group. The placement of the different stimuli on each trial was determined pseudorandomly, with the constraints that the reinforced stimulus be placed in each response chamber an equal number of times and that it not occur more than three times in succession in the same response chamber during a session.

The procedures for discrimination training are illustrated in Figure 2. Briefly, the rats were reinforced for entering the response chamber containing the correct, or reinforced $(+)$, tactile surface but were not reinforced for entering the chamber containing the incorrect, or nonreinforced (-) surface. After entering one of the response chambers, the rat was kept in that chamber for $20 \mathrm{sec}$ regardless of whether or not it was reinforced. After this interval, the chamber door was reopened, and the rat was forced to return to the common starting location for a 20 -sec intertrial interval (ITI). During the ITI, the experimenter replaced the tactile stimuli with a clean pair in preparation for the next trial; clean discriminanda were used on every trial to avoid potential odor cues left on the tactile plates. The interior of the apparatus and the textured plates were cleaned with warm water before testing the next rat.

\section{Control Procedures}

Control procedures were identical to those described for the discrimination-training group with two important exceptions. First, the rats in the control group were always presented with matching textured surfaces rather than being presented with one of each of the different textured surfaces as in the discrimination-training group. The sequence of which textured surface was presented on a given trial was determined pseudorandomly, with the constraints that each surface (toothed and crystalline) appear an equal number of times and that the same texture not appear more than three times in succession within the same session. Second, the rats in the control group were reinforced regardless of which response chamber they entered. Thus, for the rats in the control group, both chambers and both tactile surfaces were $100 \%$ reinforced.

The decision to present the rats in the control group with matching discriminanda and to reinforce them on a $100 \%$ continuous reinforcement schedule was weighed against at least two alternative control designs, both of which were dismissed for similar reasons. First, it would have been possible to present the control rats with two different tactile stimuli simultaneously, as in the discriminationtraining group, thereby equating for stimulus configuration in the apparatus on each trial. Second, it would have been possible to "yoke" each control rat to a rat in the discrimination-training group, thereby equating the number of food reinforcements for the rats in the two groups. However, if the control rats were yoked to the rats in the discrimination-training group on a session-to-session basis, it is possible that the two choice boxes (or the two textures) would develop differential reinforcement values for the rats in the control group; as training continued and the rats in the discriminationtraining group began to accrue increasing levels of reinforcement, the rats in the control group could potentially develop a preference for the side (or texture) on which it happened to receive more reinforcers. To correct this potentially confounding effect would involve dictating for the controls how many reinforcers must be received on each side (or in the presence of each texture), with the requirement that both sides (or textures) be reinforced equally. However. such a systematic and differential treatment of the control rats" behavior would require them to choose each side (or texture) an equal number of times in order to receive the same number of rein- 

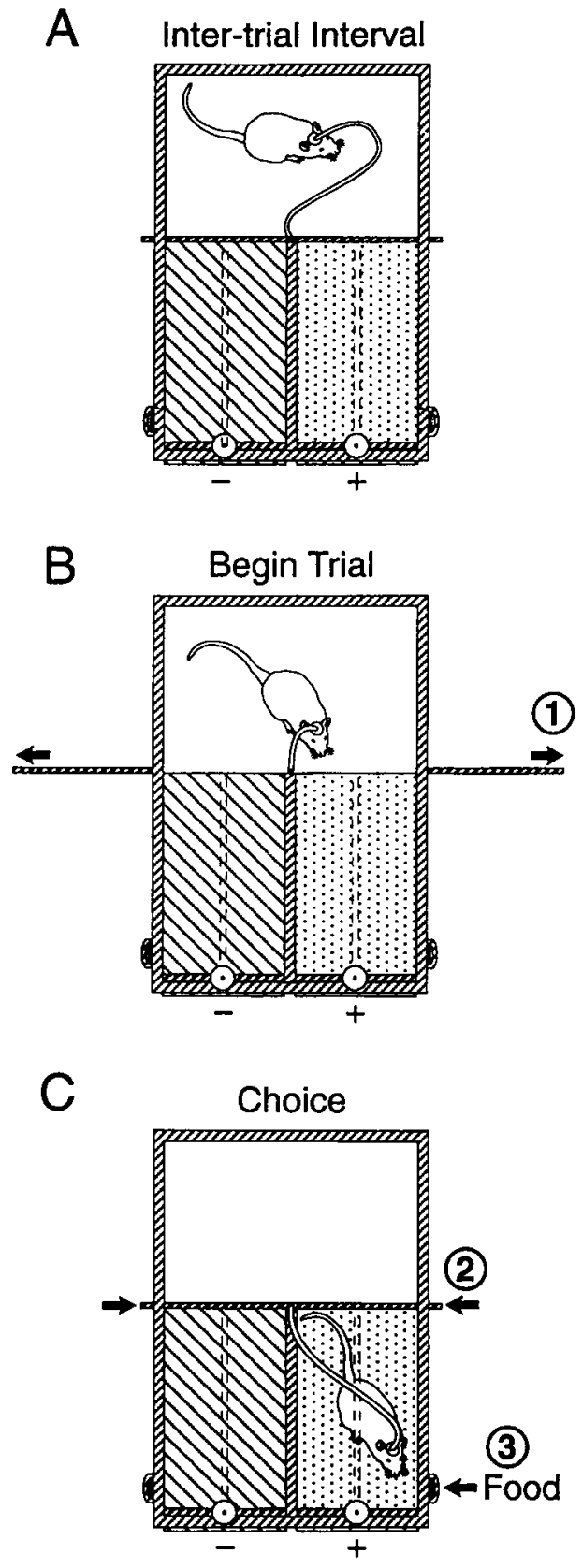

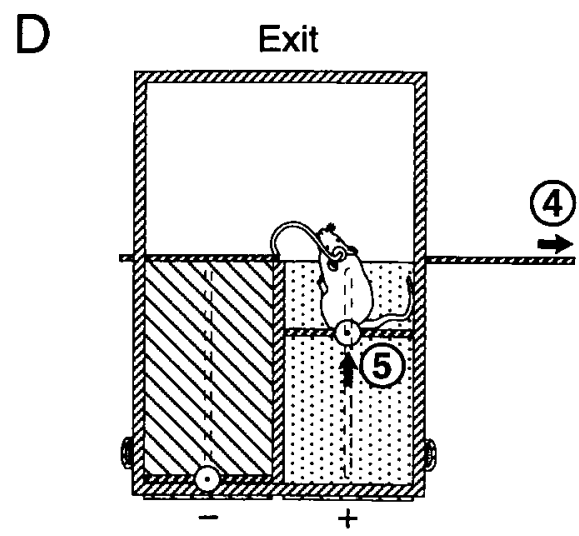

$E$

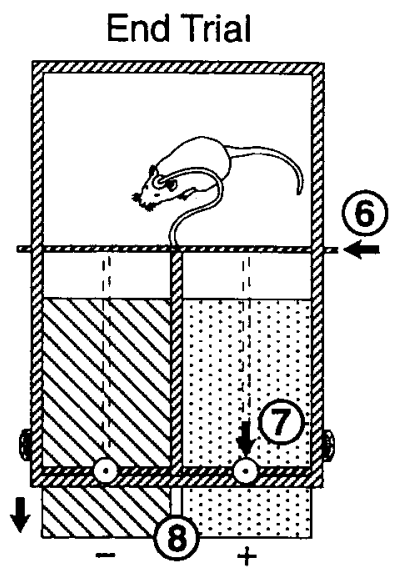

F

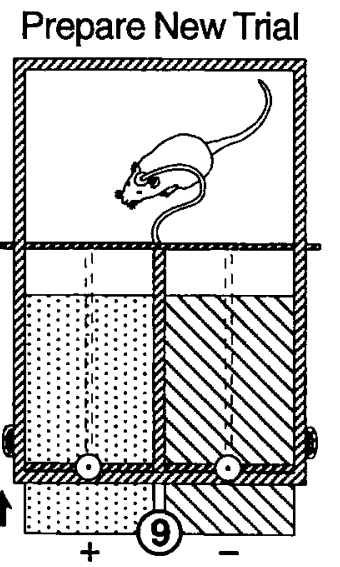

Figure 2. Illustration of the discrimination training procedure. (A) The rat is shown sitting in the starting chamber of the apparatus during the 20-sec intertrial interval (ITI) with the rat tether and plastic microtubing exiting through the lid of the apparatus. The doors to both response chambers are closed, the suspended panels used to force the rat from the response chambers are positioned at the rear of the chambers, and the reinforced $(+)$ and nonreinforced $(-)$ tactile stimuli have been inserted. (B) A trial begins by simultaneously opening both doors (1)), thereby allowing the rat access to both response chambers. (C) After the rat crosses with all four feet into a given chamber, both chamber doors are closed (2)). If the rat chooses the correct stimulus (+) as shown, it is reinforced with a piece of food (3) and allowed to remain in the response chamber for $20 \mathrm{sec}$. If the rat chooses the incorrect stimulus $(-)$, it is kept in the response chamber for 20 sec but is not reinforced. (D) After 20 sec in the selected response chamber, the door is opened (4), and the rat is gently forced back into the starting location by moving a suspended panel from the back to the front of the response chamber (5)). (E) The trial ends, and another 20-sec ITI begins when the rat returns to the starting location and the door to the selected response chamber is closed (6)). After closing the door, the experimenter returns the suspended panel to the rear of the response chamber (8) and removes the tactile discriminanda (8). (F) During the ITI, a new trial is prepared by inserting a clean pair of textured plates into the response chambers (9)). 
forcements as the rats in the discrimination training group. Because the purpose of the control group was to provide a measure of $\mathrm{ACh}$ release in the absence of specific discriminative or alternation learning, the option of using a yoked control was abandoned entirely.

Nevertheless, the $100 \%$ reinforcement/matching stimulus design presented its own set of problems; because food itself may be associated with an increase in $\mathrm{ACh}$ release in neocortex (see Inglis et al., 1994), we did not want to present one group (i.e., the control group) with more reinforcers than the other (i.e., the discrimination training group). This was especially relevant in light of our hypothesis that discrimination training would cause a greater increase in $\mathrm{ACh}$ release than would control procedures (at least in the somatosensory cortex). However, a difference in $\mathrm{ACh}$ release caused by differential exposure to reinforcement in the two groups would work against our hypothesis that the rats in the discrimination training group, which received less than $100 \%$ reinforcement, would show greater levels of $\mathrm{ACh}$ than would the rats in the control group, which received $100 \%$ reinforcement. It was ultimately decided that the advantages of the control group design selected outweighed the disadvantages in the present experimental context.

\section{Microdialysis Procedures}

Upon completion of habituation and pretraining procedures, and $24 \mathrm{~h}$ prior to beginning discrimination training or control procedures, the dummy cannulae were removed from the intracerebral microdialysis probe guides and microdialysis probes (Model CMA-12, 3 mm membrane length, Bioanalytical Systems Inc., West Lafayette, IN) filled with Ringer's solution (148 mM NaCl, $4 \mathrm{mM} \mathrm{KCl}, 1.2 \mathrm{mM} \mathrm{CaCl}, 1.2 \mathrm{mM} \mathrm{MgCl}_{2} ; \mathrm{pH} 8.0$ ) were inserted into the frontal and somatosensory cortices via the probe guides. The outlets of the microdialysis probes were kept closed with small loops of plastic tubing filled with Ringer's solution, except during microdialysis testing.

Immediately prior to beginning microdialysis testing, the loops of plastic tubing closing off the microdialysis probe inlets and outlets were removed, and the rat was connected to a lightweight tether suspended over the apparatus; the tether prevented the rat from pulling on the microdialysis tubing once connected to probes. The microdialysis probes were then perfused at a flow rate of $5 \mu \mathrm{l} / \mathrm{min}$ with Ringer's solution containing $2 \mu \mathrm{M}$ neostigmine (Sigma, St. Louis, MO) using a dual-syringe microinfusion pump (Model 22, Harvard Apparatus, South Natick, MA). The initial perfusate (i.e., "dead volume") was discarded prior to sample collection.

Baseline ACh release was measured for a period of $1 \mathrm{~h}$ in the home cage under moderate lighting and low noise levels, without available food or water on each of the 5 days of testing. After the baseline sample was obtained, the rats remained connected to the microdialysis pump and were transferred by hand from their home cage into the adjacent testing apparatus. Discrimination training or control procedures then began, and, after allowing for transit of the volume contained in the microdialysis tubing, the baseline sample vials were replaced with empty vials for discrimination training or control sample collection. A single microdialysis sample was collected for each rat during each of five daily discrimination training or control sessions (40-60 min in duration). Immediately upon completion of baseline or testing procedures, microdialysis samples were frozen in liquid nitrogen and stored at $-80^{\circ} \mathrm{C}$ until assayed.

\section{Methodological Considerations of Session-Long Microdialysis Sampling}

The decision to use a single, session-long $(40-60 \mathrm{~min})$ period of ACh sample collection was based on several factors. First, although it is possible to collect detectable amounts of ACh over periods as short as $10 \mathrm{~min}$ (e.g., Acquas et al., 1996), an analysis of potential changes in $\mathrm{ACh}$ release in the present behavioral paradigm over such short intervals would likely introduce an unwieldy variability into the data. This is because, on the basis of observations during a pilot study, behavior in the discrimination and the control paradigms was known to vary from trial to trial and from session to session. For example, on some trials, the rats would enter the response chambers very quickly without sampling the tactile discriminanda with their vibrissae, whereas, on other trials, the rats would enter the response chamber only after a prolonged sampling of the discriminanda.

Note that the procedures involved in the instrumental tactile discrimination paradigm used in the present experiment are inherently different from those involved in tests assessing the influence of classically conditioned or unconditioned stimuli on cortical ACh release (e.g., Acquas et al., 1996; Inglis \& Fibiger, 1995). In classical conditioning, sensory stimulation is tightly controlled by the experimenter, whereas, in instrumental conditioning, the animal itself has considerable control over the timing of stimulus exposure. Therefore, while it is possible to collect $\mathrm{ACh}$ samples over relatively discrete intervals in classical conditioning experiments and to relate the resulting ACh levels to some fixed level of exposure to conditioned stimuli, the same conditions do not apply in the present experimental context. Consequently, we chose to average across behaviors during the entire length of the testing session--a procedure whereby we could obtain a measure of the overall, or "net," change in ACh levels during the performance of the task across sessions as learning occurred in the discrimination training group.

Finally, although it would have been possible to delay the collection of the testing sample for several minutes after moving the rat from the home cage to the testing apparatus, thereby eliminating the influence of handling on the recovered level of $\mathrm{ACh}$ (see Acquas et al., 1996; Rosenblad \& Nilsson, 1993), we chose not to do so for the following reason. Inglis et al. (1994) showed that the anticipation of reward leads to an increase in ACh release in frontal cortex, which in the present experiment would arguably begin to peak upon placement in the starting location of the testing chamber; we did not want to exclude this possible increase from the collected sample, since it was reasonable to expect this level of anticipation to differ between groups.

\section{Methodological Considerations of Long-Term Microdialysis Sampling}

The long-term use of microdialysis techniques for quantifying neurotransmitter release in vivo over days may be complicated by the accumulation of a "glial barrier" surrounding the microdialysis membrane once it is implanted into the brain; this barrier may eventually prevent the substance under study from reaching and entering the microdialysis membrane (see Benveniste \& Diemer, 1987). Another factor affecting the long-term use of the microdialysis technique is the potential accumulation of protein on the microdialysis membrane; such an accumulation might prevent the substance under study from crossing the membrane and would decrease the efficiency of the microdialysis probe (personal communication, June 13, 1996, J. Gitzen, Bioanalytical Systems Inc., West Lafayette, IN).

Despite the potential difficulties posed by a glial barrier surrounding the probe or by the accumulation of protein around the microdialysis membrane, we were confident that the microdialysis probes used in the present study would maintain acceptable levels of function throughout the 5-day period of testing. Our confidence in the reliability of the data for ACh recovery across these 5 days is based on the following observations. First, we measured $\mathrm{ACh}$ release across a period of 10 days in a pilot study that was methodologically identical to the experiment reported here except for the longer duration of testing. Examination of this pilot data suggested that, although the absolute recovery of $\mathrm{ACh}$ diminished across days, the detected level of ACh did not reach asymptotic, floor levels until around the 7 th day of sampling; we therefore chose to limit our sampling period in the present experiment to 5 days. Second, previous research has shown that the microdialysis method allows the reliable recovery of both baseline levels and agonist-induced increases 
in serotonin for up to 7 days after microdialysis membrane implantation in the rat hippocampus (Sabol, Richards, \& Seiden, 1991). Collectively, these findings suggest that it is feasible to reliably measure neurotransmitter release over an extended period of time using microdialysis techniques.

Finally, the anatomy of the basal forebrain cholinergic system allows the measurement of $\mathrm{ACh}$ released in neocortex by probes that are far removed from the cell bodies of the nucleus basalis, which are responsible for the synthesis and release of the vast majority of ACh in the neocortex (see Fibiger, 1982; Rye, Wainer, Mesulam, Mufson, \& Saper, 1984). This arrangement makes it possible to study cortical ACh efflux in the absence of direct damage to the cells that govern the release of $\mathrm{ACh}$ - an advantage not afforded, for example, in the microdialysis of dopamine from striatum in rats (see Robinson \& Camp, 1991). To summarize, we believe that the cortical implantation of the microdialysis probes should not significantly disrupt cortical cholinergic activity, that the microdialysis probes can operate at acceptable levels for at least 5 days after implantation, and that the results obtained here should therefore be considered a valid reflection of the changes in ACh release across the duration of testing.

\section{Biochemical Analyses}

The volume of the perfusate samples was approximately $300 \mu 1$ for the samples obtained during baseline $(60 \mathrm{~min}$ at $5 \mu \mathrm{l} / \mathrm{min})$ and ranged from 200 to $300 \mu$ for the samples obtained during testing $(40-60 \mathrm{~min}$ at $5 \mu \mathrm{l} / \mathrm{min}$ ). Samples were allowed to thaw over ice before being injected into a $50-\mu l$ sample loop housed in a highpressure, liquid chromatography (HPLC) system (Bioanalytical Systems Inc., West Lafayette, IN). The HPLC system was operated at a flow rate of $1 \mathrm{ml} / \mathrm{min}$ and contained a mobile phase of $0.2 \mathrm{M}$ phosphate buffer ( $\mathrm{pH} 8.3$ ) with $1.0 \mathrm{M}$ tetramethylammonium hydroxide (Sigma, St. Louis, MO) as a preservative. Once the sample $(50 \mu \mathrm{l})$ was injected into the system, ACh was separated from choline in an analytic column ( $100 \mathrm{~mm}$ length, Chrompak, The Netherlands) and converted into hydrogen peroxide and betaine by acetylcholinesterase and choline oxidase (Sigma, St. Louis, MO) in an enzymatic reactor (Bioanalytical Systems Inc., West Lafayette, IN). The resulting hydrogen peroxide was oxidized on a platinum electrode (set to $0.5 \mathrm{~V}$ relative to the $\mathrm{Ag} / \mathrm{AgCl}$ reference electrode) and measured using an amperometric detector (Model LC4B, Bioanalytical Systems Inc., West Lafayette, IN). For details of this procedure, see Potter, Meek, and Neff (1983). Chromatograms generated by the amperometric detector were digitized and analyzed using commercially available software (GC Varian Star, Varian Canada Inc., St. Laurent, Quebec).

\section{Data Analyses}

Behavioral data from the discrimination training group were analyzed by Student's $t$ tests comparing the percent of correct responses on each of the 5 testing days to a hypothetical mean of $50 \%$ correct, or chance performance. Behavioral observations were also recorded. No statistical analyses were performed on the behavioral performance in the control group, although behavioral observations were recorded.

Biochemical data were analyzed as follows. To determine the effects of discrimination training or control conditions relative to baseline conditions, the absolute amounts of $\mathrm{ACh}$ released ( $\mathrm{fmol}$ $\mathrm{ACh} / 50-\mu \mathrm{l}$ sample) in frontal and somatosensory cortices during testing and during baseline were each analyzed independently using three-way (group $\times$ condition $\times$ day) repeated measures analyses of variance (ANOVAs; see Harris, 1985; Winer, 1971). The group factor included two levels (control group and discrimination training group), the condition factor included two levels (baseline and testing), and the day factor included five levels (one for each day of microdialysis testing). Significant main effects were followed by specific pairwise comparisons by test day using Bonferroni post hoc analyses (see Harris, 1985).
To assess differences in the magnitude of the increase in ACh released from frontal and somatosensory cortices during discrimination training or control procedures compared with baseline release, the amount of testing-induced $\mathrm{ACh}$ release in each cortical region was expressed as a percentage of the amount released during baseline on the same day for each probe in each rat. The resulting values, which reflected the percent of baseline release in each cortical region during testing, were analyzed using two-way (group $\times$ day) repeated measures ANOVAs (see Harris, 1985; Winer, 1971). Significant main effects were followed by specific pairwise comparisons by test day using Bonferroni post hoc analyses (see Harris, 1985).

This relative measure of the percent of baseline release during testing was considered to be the most useful measure for describing potential changes in $\mathrm{ACh}$ release across sessions resulting from the different behavioral treatments. Note that using this percentage-based measure allowed us to compensate for the anticipated gradual decline in the efficiency of the microdialysis probes across the 5 days of testing and to control for potential interanimal or interprobe variability in absolute $\mathrm{ACh}$ recovery. For these reasons, we relied principly upon this measure in describing the effect of discrimination training versus control procedures in our final analyses.

Lastly, to assess potential differences in the relative distribution of testing-induced cortical $\mathrm{ACh}$ release in the frontal and somatosensory cortices within each group, the difference between the percent of baseline $\mathrm{ACh}$ released during testing in the two cortical areas was calculated. Differences greater than zero reflected greater testing-induced release of $\mathrm{ACh}$ in the somatosensory cortex than in frontal cortex, whereas differences less than zero reflected the opposite pattern. A difference measure of exactly zero would reflect no difference in the magnitude of testing-induced ACh release between the two cortical regions within each group. These differences were analyzed by two-way (group $\times$ day) repeated measures ANOVAs (see Harris, 1985; Winer, 1971). Significant main effects were followed by specific pairwise comparisons by test day using Bonferroni post hoc analyses (see Harris, 1985). To determine the extent of potential differences in the relative distribution of testing-induced cortical ACh release in the frontal and somatosensory cortices within each group, the actual percent difference between the testing-induced release in the two cortical areas was compared with a hypothetical difference of zero using Student's $t$ tests for both groups on each day of testing.

\section{Histology}

Upon completion of behavioral testing, the rats were sacrificed by lethal dose of sodium pentobarbital $(80 \mathrm{mg} / \mathrm{kg}$, i.p.; Sigma, St. Louis, $\mathrm{MO}$ ) followed by cardiac perfusion with $0.9 \%$ saline and then with $10.0 \%$ formalin. Brains were extracted and placed in a $10.0 \%$ formalin and $30.0 \%$ sucrose solution for $48 \mathrm{~h}$ prior to freezing and sectioning on a sledge microtome (Model 860, American Optical Co., Buffalo, NY). Sections $(80 \mu \mathrm{m})$ were stained with thionin and examined to verify probe placement, and representative sections were photographed.

\section{RESULTS}

\section{Behavioral Observations}

Habituation and pretraining procedures appeared to be sufficient to reduce the level of stress experienced by the rats in the testing apparatus. For example, when the rats began discrimination training or control procedures, they only rarely showed signs of stress as indicated by urination or defecation in the testing apparatus. Additionally, the moving panels used to force the rats from the response chambers appeared to be well tolerated by the rats in both 
groups; the rats readily reentered the response chambers that they had recently been forced out of and quickly consumed the food reinforcements. That the rats approached the food magazines, which were situated near the moving panels at the far ends of the response chambers, and that they consumed the reinforcers immediately upon delivery suggests that they were not overly fearful of the moving panels or excessively stressed by the testing procedure.

Neither group showed exaggerated fear of the tactile stimuli when discrimination training or control procedures began; on the first 2 days, the rats in both groups entered the response chambers shortly after the doors were opened, after briefly sampling the texture of the discriminanda with their vibrissae. Once they had entered the chamber, the rats in both groups were observed to periodically whisk the surface of the tactile stimuli with their vibrissae. On the 3rd day of training, the rats in the discrimination training group (but not the control group) began to spend more time at the entrances to the response chambers sampling the tactile stimuli with their vibrissae before entering a given chamber. Over the final 2 days of training, however, as the rats in the discrimination training group became progressively more accurate in discriminating between the reinforced and nonreinforced stimuli, they spent progressively less time sampling the discriminanda before entering the response chambers. For example, if the rat first approached the correct stimulus, it might only briefly sample the texture with its vibrissae before entering the chamber for reinforcement. On occasions where the rat first approached the incorrect stimulus, it might briefly sample that stimulus and then quickly move to the correct response chamber and enter, often without stopping to sample the correct stimulus. Although behavioral data for the control animals were not systematically recorded, informal observation revealed no obvious side preference in the control animals during control testing procedures.

\section{Tactile Discrimination}

The rats in the discrimination training group solved the tactile discrimination during the 5 days of testing and were performing at greater than $80 \%$ correct on Day 5 of testing (see Figure 3). Student's $t$ tests comparing mean discrimation performance on each day with a hypothetical mean of $50 \%$ correct showed that discrimination performance was significantly greater than chance (i.e., $50 \%$ correct) on Test Day $3(t=8.49, p<.01)$, Test Day $4(t=$ $20.37, p<.001)$, and Test Day $5(t=13.27, p<.001)$, but not on Test Days 1 and 2.

\section{Absolute ACh Release During Baseline and Testing}

Baseline and testing-induced $\mathrm{ACh}$ release was expressed in terms of fmol ACh per 50- $\mu$ l of the total sample (range, 200-300 $\mu \mathrm{l}$ ), where the absolute values obtained for each $50 \mu \mathrm{l}$ sample assayed represented the average ACh release over 10 min of microdialysis sampling. Absolute $\mathrm{ACh}$ release in the frontal cortex during baseline (see Figure 4A) was compared with release during testing

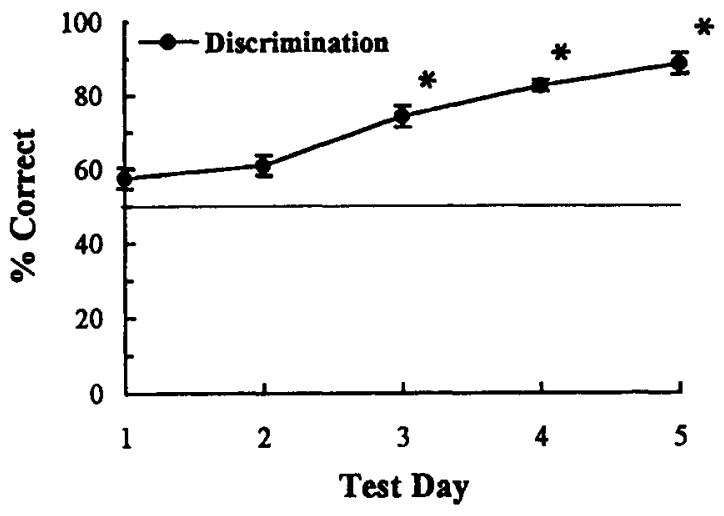

Figure 3. Performance in the tactile discrimination training group (๑) expressed as the percent of correct responses (mean $\pm S E M$ ) out of 30 trials on each test day. The rats learned the discrimination over the course of 5 days of testing; group performance was significantly greater than chance (i.e., $50 \%$ correct) on Test Days 3, 4, and $5 .{ }^{*} p<.05$.

(see Figure 4B) in each group. Three-way (group $\times$ condition $X$ day) repeated measures ANOVAs for this comparison yielded a significant within-group main effect of condition; $\mathrm{ACh}$ release was greater during testing than during baseline in both the discrimination training and the control groups $[F(1,5)=10.10, p<.025]$. Bonferroni post hoc pairwise comparisons between baseline and testing-induced release on each test day showed that this difference was significant for both groups on all test days $(p<.05)$. A significant within-group main effect of test day showed that the absolute amount of $\mathrm{ACh}$ detected in frontal cortex decreased across days in both groups during both baseline and testing conditions $[F(4,20)=4.01$, $p<.015]$.

No other significant effects were observed in comparisons of frontal cortex ACh release. Although the discrimination training group appeared to have greater levels of testing-induced release than did the controls, this difference was not significant, perhaps due to the relatively low $n$ in both groups. Importantly, however, when testing-induced $\mathrm{ACh}$ release was expressed as a percent of baseline release, thereby eliminating interanimal and interprobe variability in each group, the apparent betweengroup difference in testing-induced frontal cortex $\mathrm{ACh}$ release was nearly eliminated (see below). This reduction in apparent group differences in testing-induced $\mathrm{ACh}$ release in frontal cortex was likely due to the moderately higher baseline levels of ACh release observed in the discrimination training group.

Absolute $\mathrm{ACh}$ release in the somatosensory cortex during baseline (see Figure 4C) was also compared with release during testing (see Figure 4D) in each group. Three-way (group $\times$ condition $\times$ day) repeated measures ANOVAs for this comparison similarly yielded a significant within-group main effect of condition; ACh levels were greater during testing than during baseline measures in both the discrimination training and the control groups $[F(1,5)=32.46, p<.002]$. Bonferroni post 


\section{Frontal Cortex}

$\mathbf{A}$

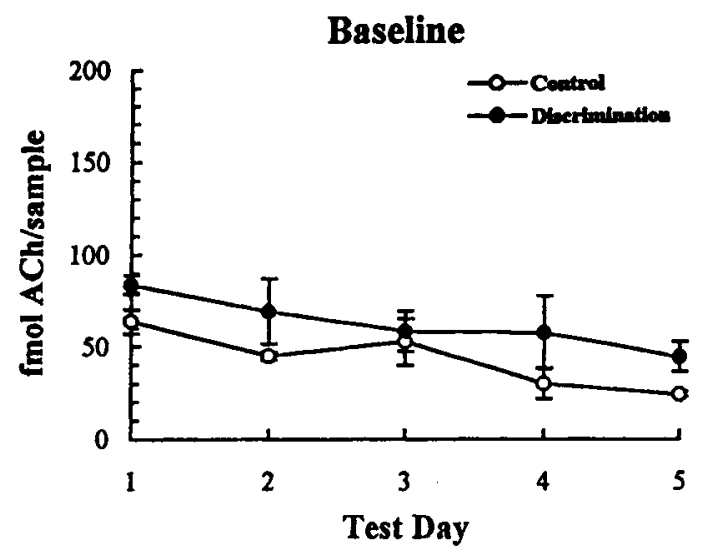

B

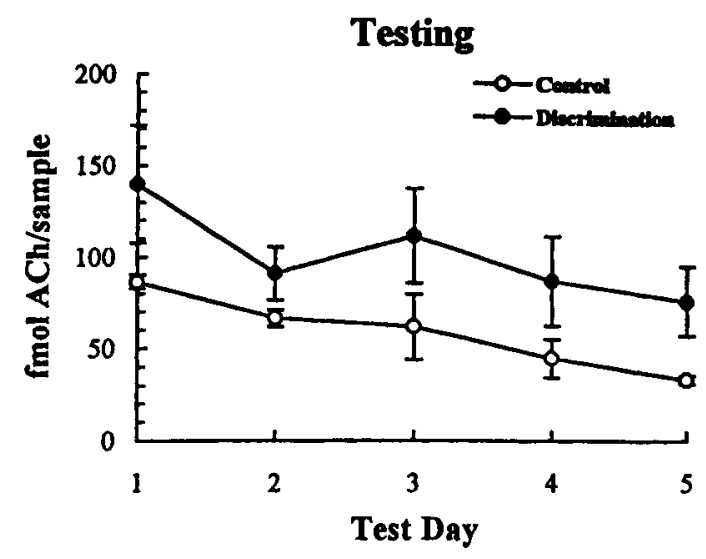

\section{Somatosensory Cortex}

C

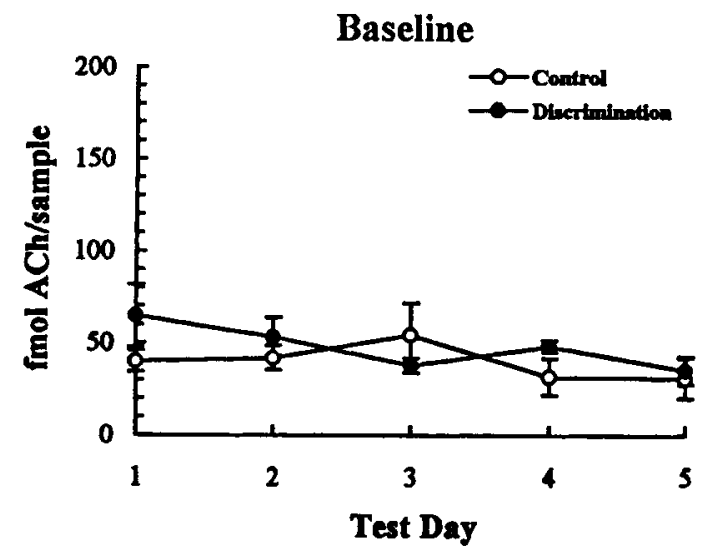

D

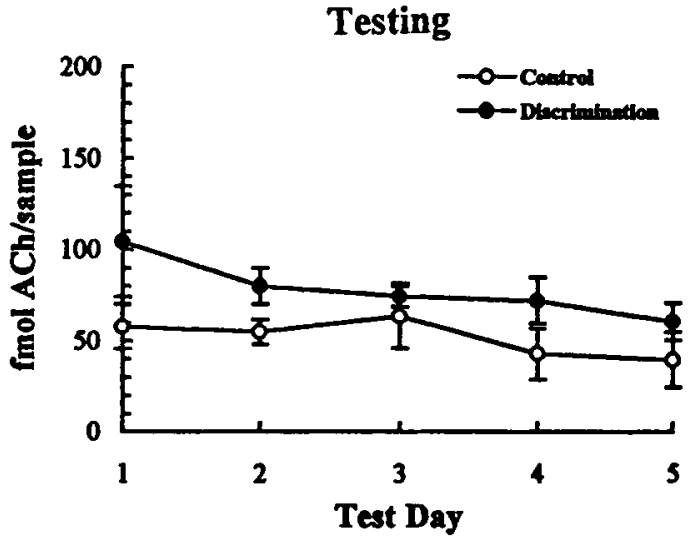

Figure 4. Absolute values (mean \pm SEM) of ACh release in frontal and somatosensory cortices of the discrimination training (•) and control $(O)$ groups during baseline and during testing conditions. (A) Baseline levels of ACh release in frontal cortex did not differ between groups. (B) Compared with baseline release within each group, the level of ACh released in the frontal cortex during testing increased on all test days $(p<.05)$. Although the discrimination training group appeared to have higher mean levels of $\mathrm{ACh}$ release in the frontal cortex during testing, groups did not differ significantly on this measure. (C) Baseline levels of ACh release in somatosensory cortex did not differ between groups. (D) Compared with baseline release within each group, the level of $\mathrm{ACh}$ released in the somatosensory cortex during testing increased on all test days $(p<.05)$. Additionally, a between-group comparison showed that the rats in the discrimination training group had higher levels of testing-induced $\mathrm{ACh}$ release in somatosensory cortex across test days than did the controls $(p<.05)$. Note that the absolute level of $\mathrm{ACh}$ detected in the frontal cortex of both groups diminished across test days, both during baseline and during testing conditions $(p<.05)$; a similar trend occurred in the somatosensory cortex, although the effect of test day was not significant $(p<.12)$. The decrease in the absolute amount of $\mathrm{ACh}$ recovered suggests a gradual decline in the efficiency of the microdialysis probes over test days.

hoc pairwise comparisons between baseline and testinginduced release on each day showed that this difference was significant for both groups on all test days $(p<.05)$. A significant group $\times$ condition interaction effect revealed that, although $\mathrm{ACh}$ release did not differ between groups during baseline, the amount of $\mathrm{ACh}$ released in the somatosensory cortex was greater during testing in the discrimination training group than in controls $[F(1,5)=$ $7.26, p<.043$ ]. No other significant effects were ob- served in comparisons on somatosensory cortex ACh release, although the within-group main effect of test day approached significance $(p<.12)$.

\section{Testing-Induced ACh Release Expressed as a Percent of Baseline Release}

Two-way (group $X$ day) repeated measures ANOVAs on testing-induced $\mathrm{ACh}$ release expressed as a percent of baseline $\mathrm{ACh}$ release in the frontal cortex yielded no 
significant effects, suggesting no differences between groups or across test days (see Figure 5A). However, the same analysis on data from the somatosensory cortex provided a significant main effect of group $[F(1,5)=11.6$, $p<.019]$; the percent of baseline ACh release in somatosensory cortex during testing was significantly greater in the discrimination training group than in controls (see Figure 5B). Bonferroni post hoc pairwise comparisons between groups on each day showed that this difference was significant only on the last 3 days of testing $(p<.05)$. No other significant effects were observed.

\section{Relative Distribution of Testing-Induced ACh Release in Frontal and Somatosensory Cortices}

Compared with controls, the discrimination training group showed a proportionately larger amount of testinginduced $\mathrm{ACh}$ release in somatosensory cortex relative to release in the frontal cortex (see Figure 6). Two-way (group $x$ day) repeated measures ANOVAs on the difference between the percent of baseline $\mathrm{ACh}$ release in somatosensory cortex and in frontal cortex within each group revealed a significant between-group main effect $[F(1,5)=$ $9.8, p<.026$ ]; the discrimination training group had significantly greater levels of ACh release in their somatosensory cortex than in their frontal cortex, relative to controls. No significant post hoc effects and no other significant main effects were observed on this measure. Although ANOVAs showed that the discrimination training group differed from the control group on this measure, Student's $t$ tests comparing the difference in testinginduced $\mathrm{ACh}$ release between cortical areas to a hypothetical mean difference of zero showed that neither group had differences that were reliably different from zero.

\section{Histology}

Histological examination confirmed that the anterior microdialysis probes were consistently located in the lower

\section{Frontal Cortex}

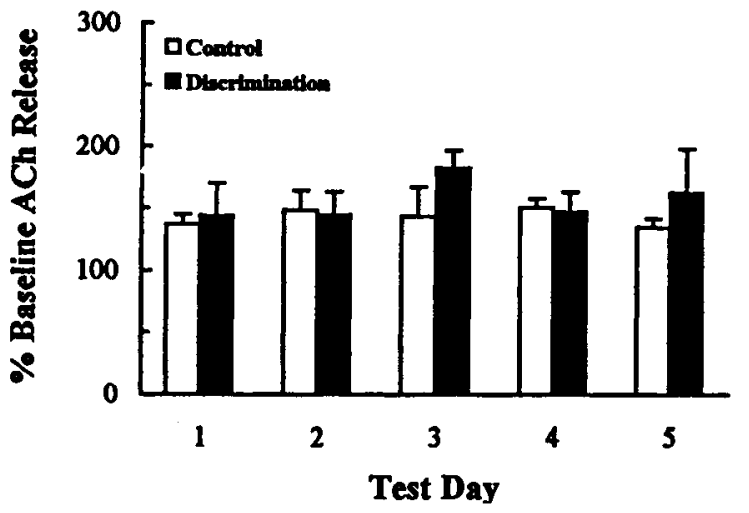

layers of the frontal cortex and the posterior probes were consistently located in the lower layers of the vibrissae region in the somatosensory cortex, at approximately $1.4 \mathrm{~mm}$ anterior and $2.6 \mathrm{~mm}$ posterior to bregma, respectively (see Figure 7). The 3-mm exposed membrane tips of the microdialysis probes came to rest in the cortical tissue above the corpus callosum in the infragranular layers of cortex. The exposed microdialysis membrane extended ventrolaterally through the cortical mantle from $\sim 4.0-7.0 \mathrm{~mm}$ lateral to midline, passing through layers IV, $\mathrm{V}$, and VI of the cortex at varying points along the length of the probe. Probe sites were characterized by gliosis around the tract created by the probe and probe guide.

\section{DISCUSSION}

The results confirmed our hypothesis that $\mathrm{ACh}$ release would be greater during discrimination training and control procedures than during baseline measures in the home cage; both groups released more ACh during behavioral testing relative to release during baseline, not only in the frontal cortex but also in the somatosensory cortex. The results also confirmed our hypothesis that $\mathrm{ACh}$ release in the somatosensory cortex would be greater during testing in the discrimination training group than in the control group; the discrimination training group had greater levels of testing-induced ACh release in the somatosensory cortex than did the controls. This difference was significant only on the last 3 days of testing, when the rats in the discrimination training group had learned to solve the task. Additionally, the results showed that, compared with controls, the discrimination training group released more $\mathrm{ACh}$ in their somatosensory cortex relative to their frontal cortex during testing. Collectively, these results suggest that, in addition to the widespread enhancement of $\mathrm{ACh}$ release associated with appetitive conditioning procedures in general, tactile discrimination training causes a region-

\section{B Somatosensory Cortex}

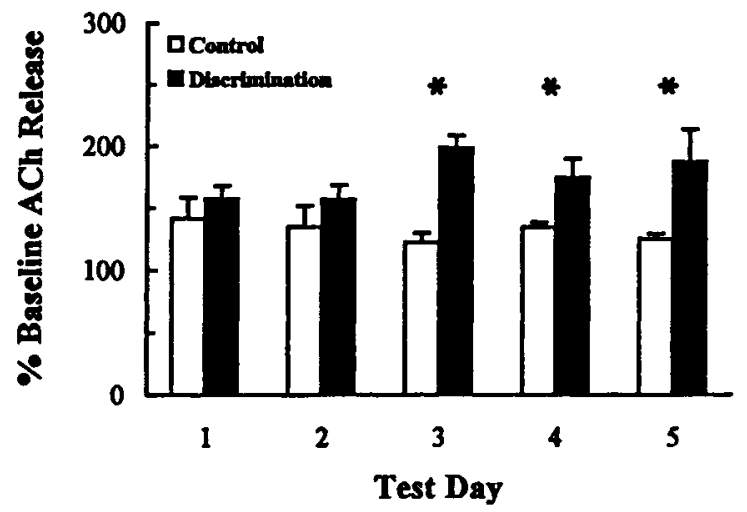

Figure 5. Testing-induced $\mathrm{ACh}$ release in frontal and somatosensory cortices expressed as a percent (mean $\pm S E M$ ) of baseline release in the discrimination training ( $(\square)$ and control ( $\square$ ) groups. (A) Both groups showed greater levels of $\mathrm{ACh}$ release in the frontal cortex during testing relative to baseline release, but these levels did not differ significantly between groups. (B) Both groups showed greater levels of $\mathrm{ACh}$ release in the somatosensory cortex during testing relative to baseline release, but the rats in the discrimination training group showed an even greater testing-induced increase in ACh release than did the controls on Test Days 3,4 , and $5 .{ }^{*} p<.05$. 


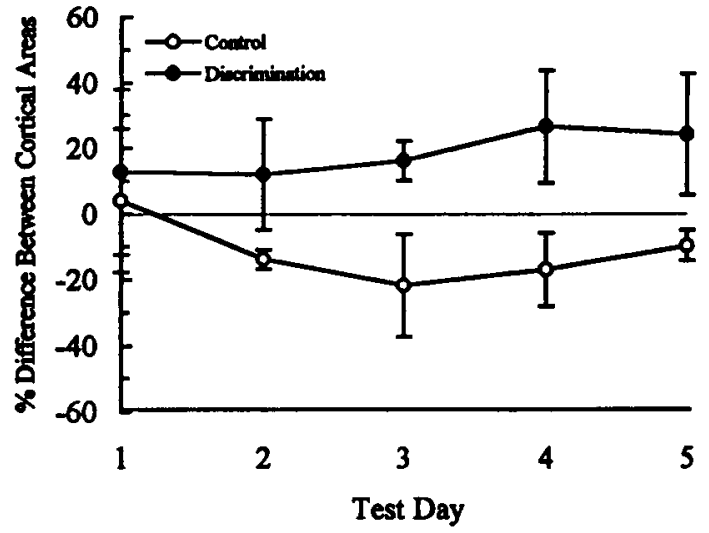

Figure 6. Relative distribution of $\mathrm{ACh}$ release during testing as reflected by the difference (mean $\pm S E M$ ) between the testinginduced $A C h$ release (percent of baseline) observed in the somatosensory and frontal cortices within the discrimination training $(\bullet)$ and control $(0)$ groups. The rats in the discrimination training and control groups differed significantly on this measure $(p<.05)$. Note that the rats in the discrimination training groups consistently had greater testing-induced increases in $\mathrm{ACh}$ release in their somatosensory cortex than in their frontal cortex (reflected by positive differences). The rats in the control group, in contrast, had greater testing-induced increases in $\mathrm{ACh}$ release in their frontal cortex than in their somatosensory cortex (reflected by negative differences), except on the 1st day of testing when the tactile stimuli were novel.

ally specific enhancement in ACh release in the somatosensory cortex that is related to discrimination performance. It should be mentioned, though, that while the observed differences in $\mathrm{ACh}$ levels most likely reflect differences in $\mathrm{ACh}$ release, the concentration of $\mathrm{ACh}$ in the perfusate may have been influenced by other metabolic changes (e.g., decreased acetylcholinesterase activity).

The increase in ACh release observed in both cortical regions in both groups during testing was likely related to several factors affecting both groups, including the brief handling at the beginning of testing (see Acquas et al., 1996; Rosenblad \& Nilsson, 1993), the increase in motor activity (see Day et al., 1991) and sensory stimulation associated with the testing procedures (see Inglis \& Fibiger, 1995; Kurosawa et al., 1992), and the conditioned expectation and actual consumption of food reinforcement (see Inglis et al., 1994; Moore et al., 1993). That ACh release in both the frontal and the somatosensory cortices was influenced by these appetitive conditioning procedures suggests that $\mathrm{ACh}$ release associated with arousal occurs globally, throughout neocortex.

The finding of a testing-induced increase in ACh release in frontal cortex is consistent with previous reports where rats were trained to anticipate food in a particular environment or in the presence of specific conditioned stimuli (e.g., Inglis et al., 1994; Moore et al., 1993). It has been suggested that the frontal cortex is involved in the recognition of conditioned stimuli and that $\mathrm{ACh}$ is released in the frontal cortex in response to the presentation of such stimuli (Inglis et al., 1994; Pirch, Turco, Rucker, 1992). Electrophysiological data also suggest cholinergic involve- ment in frontal cortex activity that is related to memory. For example, cells in the rat NBM and NBM target cells in the frontal cortex respond differentially to the presentation of conditioned visual stimuli (Pirch, 1993; Pirch et al., 1990; Rigdon \& Pirch, 1986). Thus, the frontal cortex appears to play an important role in associative conditioning.

In this context, it is perhaps surprising that the discrimination training group did not show significantly greater testing-induced $\mathrm{ACh}$ release in the frontal cortex relative to controls. One group was required to make a discrimination between differentially reinforced stimuli, whereas the other group simply received noncontingent reinforcement; therefore, one might have expected differences in the amount of ACh released in the frontal cortex of each group. However, no such difference was observed; this lack of effect may be interpreted in a number of ways, including the possibility that learning the discrimination did not critically involve frontal cortex, or the possibility that the testing-induced release of ACh seen in the frontal cortex of the control group was so high that it "masked" any potential differences between the two groups. Despite the absence of a significant between-group difference in testing-induced $\mathrm{ACh}$ release in the frontal cortex, our data are nonetheless consistent with those of previous studies suggesting that behavioral conditioning evokes the release of ACh from basal forebrain neurons into frontal cortex when animals are presented with conditioned stimuli (e.g., Inglis et al, 1994; Moore et al., 1993). As discussed previously, however, we cannot attribute the observed testinginduced increase in ACh release in frontal cortex exclusively to associative factors, since increased movement and sensory stimulation, as well as arousal associated with the availability of food, were inherent to the testing situation; these factors likely combined to exert some influence on ACh release in both groups.

The testing-induced increase in ACh release in the somatosensory cortex seen in both groups suggests that the influence of appetitive conditioning procedures on $\mathrm{ACh}$ release is not restricted to the frontal cortex. Although previous research has shown that $\mathrm{ACh}$ release in somatosensory cortex increases in response to tactile stimulation (Kurosawa et al., 1992) or during the change from sleep to wakefulness (Jiménez-Capdeville \& Dykes, 1993), a similar increase associated with appetitive conditioning procedures has not been previously reported. As with the testing-induced increase in $\mathrm{ACh}$ release in frontal cortex, however, the increase in ACh release observed in somatosensory cortex of both groups cannot be exclusively attributed to associative factors but must also be partly attributed to increased motor and sensory activity and to increased arousal associated with the availability of food.

The rats in the discrimination training group showed significantly greater levels of testing-induced $\mathrm{ACh}$ release in the somatosensory cortex than did the controls; however, as previously discussed, ACh levels in both groups were higher during testing than during baseline. We attribute the greater testing-induced ACh release in the somatosensory cortex seen in the rats of the discrimination 

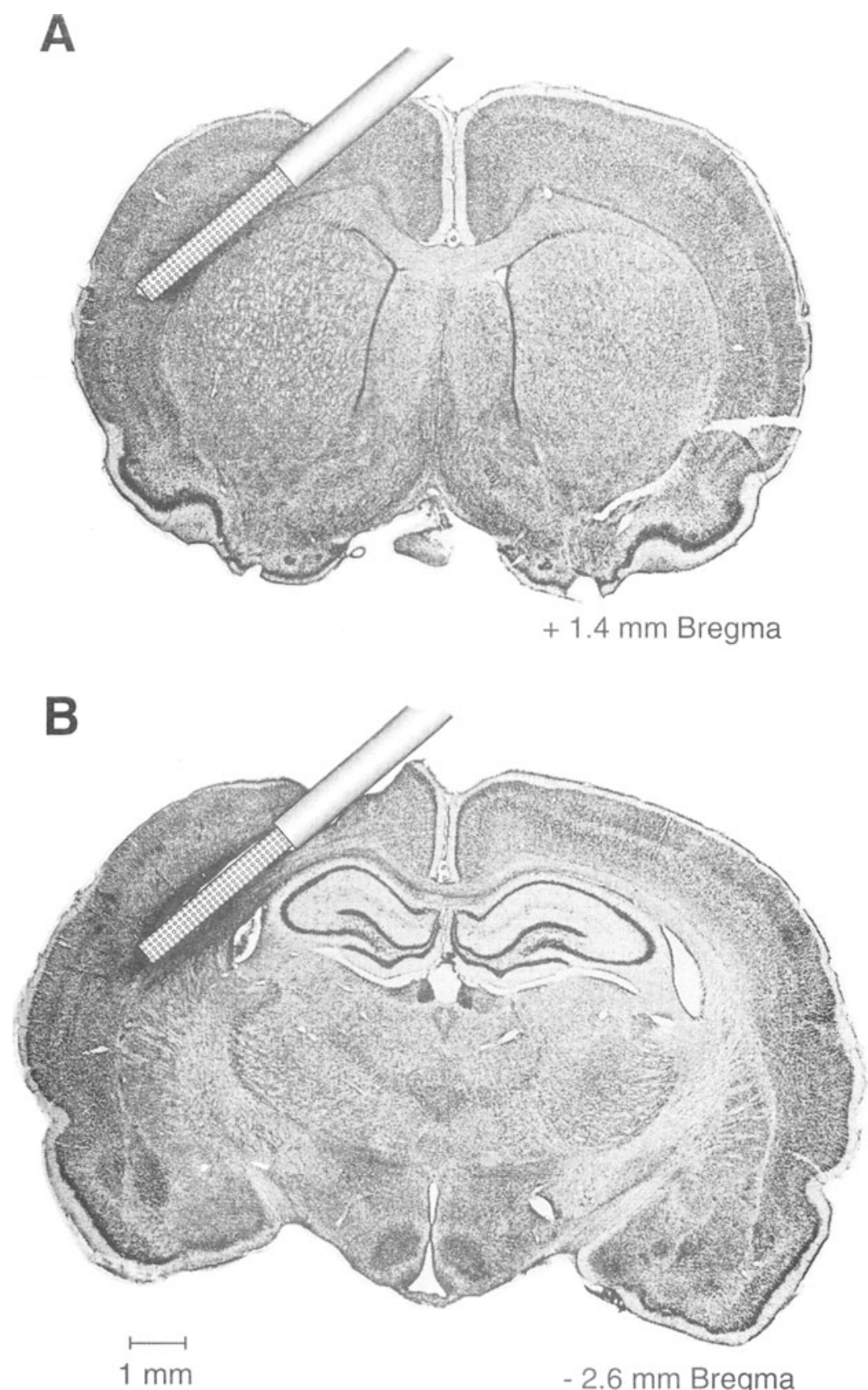

Figure 7. Representative thionin-stained sections $(80 \mu \mathrm{m})$ from the frontal (A) and somatosensory (B) cortices, with illustrations of the microdialysis probes superimposed over the tracts created by the probes and probe guides. The exposed microdialysis membrane was positioned above the corpus callosum, in infragranular layers IV, $V$, and VI of the frontal and somatosensory cortices. Probe sites were characterized by gliosis around the probe membrane and guide cannulae.

training group to the fact that they were actively engaged in learning to discriminate between tactile surfaces using their vibrissae. Because tactile discrimination in rats typically depends on activity in the vibrissae representation of the somatosensory cortex (see Guic-Robles et al., 1992; Wozniak et al., 1989), we expected ACh release in the somatosensory cortex to be greater in the tactile discrimination training group than in the controls; the difference in testing-induced $\mathrm{ACh}$ release in the somatosensory cortex observed between the discrimination training and control groups confirmed this expectation. These results suggest that, in addition to the more global increase in ACh release in the neocortex caused by appetitive conditioning procedures in both groups, tactile discrimination training caused a regionally specific and taskdependent modulation of cortical ACh release. 
There are at least two alternative interpretations of the between-group difference in the amount of testinginduced $\mathrm{ACh}$ release in the somatosensory cortex that warrant consideration. First, the rats in the discrimination training group may have simply been receiving more sensory stimulation than were the controls because they were required to actively sample the discriminative tactile stimuli in order to determine their reinforcement contingencies. Since somatosensory stimulation is known to increase ACh release in rats (e.g., Inglis \& Fibiger, 1995), this difference in procedural requirements could be argued to account for the observed difference in testing-induced ACh release in the somatosensory cortex. In fact, during the early stages of acquisition, the rats in the discrimination training group did spend more time sampling the textures of the discriminanda with their vibrissae than did the controls. However, as the rats in the discrimination training group began to solve the task, they spent progressively less time sampling the discriminanda; once these rats had determined the reinforcement contingencies associated with each tactile stimulus, they had only to sample the stimulus very briefly before making their choice of response chambers. Furthermore, because the betweengroup difference in testing-induced $\mathrm{ACh}$ release in the somatosensory cortex emerged on the 3rd day of testing and persisted through the 4 th and 5 th days, when stimulus sampling was greatly reduced and discrimination performance levels were highest, we must argue that this difference was due to learning-specific processes in the discrimination training group rather than to an increase in sensory stimulation alone.

A second possible interpretation of the between-group difference seen in testing-induced ACh release in the somatosensory cortex involves the potential increase in arousal or "frustration" experienced by the discrimination training group but not by the control group. Because the reinforcement contingencies for the control group did not change during the transition from pretraining to testing conditions, the controls were not particularly challenged by the new testing procedures. The discrimination training group, however, was subjected to a decrease in reinforcement during discrimination testing relative to the continuous reinforcement they received during pretraining. This change in reinforcement contingencies may have caused an increase in arousal, perhaps associated with the frustration of nonreward (see Amsel, 1992). Arousal is known to influence cortical ACh release (e.g., Acquas et al., 1996; Inglis \& Fibiger, 1995; Jiménez-Capdeville \& Dykes, 1993); therefore, the difference in reinforcement schedules experienced by the two groups may have been responsible for the observed differences in ACh release. According to such an argument, arousal would be expected to be greatest early in testing, when the level of reinforcement earned in the discrimination training group was lowest and the contrast in reinforcement relative to pretraining conditions was highest. However, the greatest increases in ACh release in somatosensory cortex occurred later in testing, when rats in the discrimination training group had begun to solve the task and were receiving higher levels of reinforcement than they were at the beginning of testing. Furthermore, frustration-induced arousal might be expected to cause an increase in ACh release in the frontal cortex as well as in the somatosensory cortex; however, the data show that groups did not differ in testing-induced ACh release in frontal cortex. These results again suggest that the observed difference in testinginduced $\mathrm{ACh}$ release in somatosensory cortex was due primarily to the experience of learning the tactile discrimination rather than to arousal associated with nonreward.

In addition to the between-group differences in ACh release observed in somatosensory cortex, there was a between-group difference in the relative amount of testinginduced $\mathrm{ACh}$ release in the somatosensory and frontal cortices. The rats in the discrimination training group consistently had greater testing-induced increases in ACh release in their somatosensory cortex than in their frontal cortex, whereas the rats in the control group showed the opposite pattern, except on the 1st day of testing. It is possible that the increase in ACh release in the somatosensory cortex in the control group was apparently higher than in their frontal cortex on the 1st day of testing because of the relative novelty of the tactile stimuli when they were first introduced; this novelty may have led to a transient increase in somatosensory cortical activity that dissipated as testing continued (see Acquas et al., 1996).

Although the discrimination training and control groups differed significantly in terms of the relative differences in testing-induced $\mathrm{ACh}$ release in the frontal and somatosensory cortices, neither within-group differences across testing days nor individual comparisons against the null hypothesis of zero differences in $\mathrm{ACh}$ release between the two cortical areas in a given group on a given test day were significant. Nevertheless, data comparing the extent of testing-induced $\mathrm{ACh}$ release in the frontal and somatosensory cortices within the same animals suggest that, depending on the nature of the behavioral task an animal is engaged in, ACh may not always be released homogeneously throughout neocortex. Instead, ACh may be released in a regionally specific manner, with proportionately greater release in taskrelevant sensory cortices than in other cortical regions. The corticotopic organization of NBM projections to neocortex (see Rye et al., 1984) would appear to allow such regional specificity in ACh release, and, indeed, recent evidence supports the contention that $\mathrm{ACh}$ can be differentially released in various cortical regions (see Jiménez-Capdeville, Dykes, \& Myasnikov, in press). We believe that the potential for the differential release of ACh in the neocortex under different behavioral conditions warrants further study.

Differential release of ACh during learning may serve to modulate selective attention (see Butt \& Hodge, 1995; Chiba et al., 1995; Muir et al., 1993; Pang et al., 1993; Robbins et al., 1989), perhaps by enhancing the responsiveness of cortical cells to specific sensory inputs while ACh is still present at the synapse (see Donoghue \& Carroll, 1987; Metherate \& Ashe, 1991). Furthermore, differential release of ACh may preferentially influence long- 
lasting cortical plasticity in those sensory cortices that are involved in solving a particular task. Others have shown that cholinergic activation can facilitate the formation of long-lasting, experience-dependent changes in the response properties of neocortical sensory neurons in a variety of contexts (see Baskerville, Heaston, Schweitzer, \& Herron, 1995; Bear \& Singer, 1986; Juliano, Ma, Bear, \& Eslin, 1990; Metherate, Tremblay, \& Dykes, 1988a, 1988b; Pirch, 1993; Rasmusson \& Dykes, 1988; Tremblay, Warren, \& Dykes, 1990; Webster, Hanisch, Dykes, \& Biesold, 1991; Weinberger, 1993; Weinberger et al., 1990). For example, ACh-dependent associative plasticity has been described in the guinea pig auditory cortex, where classical conditioning in auditory cortical neurons was found to depend on the convergent activation of acoustic thalamocortical and NBM cholinergic modulatory inputs (Weinberger et al., 1990).

Associatively induced synaptic plasticity also occurs in vibrissae barrel field neurons in the somatosensory cortex of rats tested in classical conditioning (see Kossut, 1992), conditioned suppression (Hutson \& Masterton, 1986), and sensory preconditioning paradigms (Delacour et al., 1990a, 1990b; Delacour et al., 1987). In addition to its role in auditory cortex (see Weinberger et al., 1990), cholinergic modulation appears to be critical in the development of associatively induced plasticity in the barrel field cortex (e.g., Baskerville et al., 1995; Delacour et al., 1990a). On the basis of these findings, it is possible that the enhancement seen in $\mathrm{ACh}$ release in the somatosensory cortex of rats learning a tactile discrimination in the present experiment may have preferentially contributed to synaptic plasticity within the barrel field cortex as these rats learned to solve the behavioral task.

Regionally specific cholinergic enhancement of cortical synaptic plasticity may critically contribute to representational memory formation by strengthening those synapses that are involved in the representation of particular conditioned stimuli (see Bakin \& Weinberger, 1990; Dykes, 1990; Jenkins, Merzenich, Ochs, Allard, \& GuicRobles, 1990; Merzenich \& Jenkins, 1993; Merzenich, Recanzone, Jenkins, Allard, \& Nudo, 1988; Recanzone, Schreiner, \& Merzenich, 1993; Weinberger, 1995; Weinberger \& Diamond, 1987). This suggestion derives in part from the findings of Dykes and colleagues, who have characterized cholinergically mediated, experiencedependent plasticity, or long-term cholinergic enhancement (LTCE), as a special instance of long-term potentiation (LTP) occurring in neocortex (see Dykes, 1990; Dykes, Tremblay, Warren, \& Bear, 1991; Verdier, Maalouf, Myasnikov, \& Dykes, 1995). Hippocampal LTP has been proposed as a principal mechanism for memory storage (Brown, Chapman, Kairiss, \& Keen, 1988; Collingridge \& Davies, 1989; Morris, Anderson, Lynch, \& Baudry, 1986; Morris, Davis, \& Butcher, 1989; Roman, Chaillan, \& Soumireu-Mourat, 1993; but see Barnes, 1995; Nosten-Bertrand et al., 1996; Saucier \& Cain, 1995), and it is argued that neocortical LTCE may serve a similar function in learning and memory (Dykes, 1990; also see Weinberger, 1995).
In conclusion, we suggest that the increase in ACh release seen in the frontal and somatosensory cortices of discriminating and nondiscriminating rats undergoing appetitive conditioning procedures reflects a combination of factors, including increased motor and sensory activity, as well as the conditioned expectation and consumption of food reinforcement. Moreover, we suggest that the greater levels of testing-induced $\mathrm{ACh}$ release in the somatosensory cortex observed in the discrimination training group, relative to those observed in the controls, reflects a regionally specific and task-dependent modulation in cortical $\mathrm{ACh}$ release and that this modulation is importantly related to task performance. Finally, we suggest that the enhanced release of $\mathrm{ACh}$ may contribute to tactile discrimination learning by encouraging LTCE in those neocortical synaptic networks involved in the representation of the conditioned stimuli. We believe that $\mathrm{ACh}$ dependent, associatively induced neocortical synaptic plasticity should be further explored in experiments examining the relationships between ACh release, changes in synaptic efficacy, and the development of learned behaviors. Such experiments should contribute to our knowledge of the neural basis of representational memory in general and enhance our understanding of cholinergic involvement in learning and memory in particular.

\section{REFERENCES}

Acquas, E., Wilson, C., \& Fibiger, H. C. (1996). Conditioned and unconditioned stimuli increase frontal cortical and hippocampal acetylcholine release: Effects of novelty, habituation, and fear. Journal of Neuroscience, 16, 3089-3096.

AMsel, A. (1992). Frustration theory: Many years later. Psychological Bulletin, 112, 396-399.

Bakin, J. S., \& WeinBerger, N. M. (1990). Classical conditioning induces CS-specific receptive field plasticity in the auditory cortex of the guinea pig. Brain Research, 536, 271-286.

BARNES, C. A. (1995). Involvement of LTP in memory: Are we "searching under the street light"? Neuron, 15, 751-754.

Baskerville, K. A., Heaston, N. R., Schweitzer, J. B., \& Herron, P. (1995). Role of acetylcholine in experience-dependent plasticity in the somatosensory cortex of the rat. Society for Neuroscience $A b$ stracts, 21, 123.

BEAR, M. F., \& Singer., W. (1986). Modulation of visual cortical plasticity by acetylcholine and noradrenaline. Nature, 320, 172-176.

Beninger, R. J., Wirsching, B. A., Jhamandas, K., Boegman, R. J. \& El Defrawy, S.R. (1986). Effects of altered cholinergic function on working and reference memory in the rat. Canadian Journal of Physiology \& Pharmacology, 64, 376-382.

Benveniste, H., \& Diemer, H. H. (1987). Cellular reactions to implantation of a microdialysis tube in the rat hippocampus. Acta Neuropathologica, 74, 234-238.

Brown, T. H., Chapman, P. F., Kairiss, E. W., \& Keen, C. L, (1988). Long-term synaptic potentiation. Science, 242, 724-728.

ButT, A. E., \& HODGE, G. K. (1995). Acquisition, retention, and extinction of operant discriminations in rats with bilateral ibotenic acid lesions of the nucleus basalis magnocellularis. Behavioral Neuroscience, 109, 699-713.

ChapIN, J. K., \& LiN, C. S. (1984). Mapping the body representation in the SI cortex of anesthetized and awake rats. Journal of Comparative Neurology, 299, 199-213.

Chiba, A. A., Bucci, D. J., Holland, P. C., \& Gallagher, M. (1995). Basal forebrain cholinergic lesions disrupt increments but not decrements in conditioned stimulus processing. Journal of Neuroscience, 15, 7315-7322.

Collingridge, G. L., \& Davies, S. N. (1989). NMDA receptors and 
long-term potentiation in the hippocampus. In J. C. Watkins \& G. L. Collingridge (Eds.), The NMDA receptor (pp. 123-136). New York: IRL.

Day, J., Damsma, G., \& Fibiger, H. C. (1991). Cholinergic activity in the rat hippocampus, cortex, and striatum correlates with locomotor activity: An in vivo microdialysis study. Pharmacology, Biochemistry \& Behavior, 38, 723-729.

DeKKER, A. J., ConNOR, D. J., \& ThaL, L. J. (1991). The role of cholinergic projections from the nucleus basalis in memory. Neuroscience \& Biobehavioral Reviews, 15, 299-317.

Delacour, J., Houcine, O., \& Costa, J. C. (1990a). Evidence for a cholinergic mechanism of "learned" changes in the responses of barrel field neurons of the awake and undrugged rat. Neuroscience, 34, $1-8$.

Delacour, J., Houcine, O., \& Costa, J. C. (1990b). Modifications of the responses of barrel field neurons to vibrissal stimulation during theta in the awake and undrugged rat. Neuroscience, 37, 237-243.

Delacour, J., Houcine, O., \& TALBI, B. (1987). "Learned" changes in the responses of the rat barrel field neurons. Neuroscience, 23, 63-71.

Diamond, M., Armstrong-James, J., \& EbNer, F. (1993). Experiencedependent plasticity in adult rat barrel cortex. Proceedings of the National Academy of Sciences, 90, 2082-2086.

Donoghue, J. P., \& CARRoll, K. L. (1987). Cholinergic modulation of sensory responses in rat primary somatic sensory cortex. Brain Research, 408, 367-371.

Dubois, B., Mayo, W., Agid, Y., LeMoal, M., \& Simon, H. (1985). Profound disturbances of spontaneous and learned behaviors following lesions of the nucleus basalis magnocellularis in the rat. Brain Research, 338, 249-258.

Dunnett, S. B., Everitt, B. J., \& Robins, T. W. (1991). The basal forebrain-cortical cholinergic system: Interpreting the functional consequences of excitotoxic lesions. Trends in Neurosciences, 14, 494-501.

DYKES, R. W. (1990). Acetylcholine and neuronal plasticity in somatosensory cortex. In M. Steriade \& D. Biesold (Eds.), Brain cholinergic systems (pp. 294-313). New York: Oxford University Press.

Dykes, R. W., Tremblay, N., Warren, R., \& Bear, M. (1991). Cholinergic modulation of synaptic plasticity in sensory neocortex. In R. Richardson (Ed.), Activation to acquisition: Functional aspects of the basal forebrain cholinergic system (pp. 328-342). Cambridge, MA: Birkhauer.

Fibiger, H. C. (1982). The organization and some projections of cholinergic neurons of the mammalian forebrain. Brain Research Review, 4, 327-388.

Fibiger, H. C. (1991). Cholinergic mechanisms in learning, memory, and dementia: A review of recent evidence. Trends in Neurosciences, 14, 220-223.

Guic-Robles, E., Jenkins, W. M., \& Bravo, H. (1992). Vibrissal roughness discrimination is barrel cortex-dependent. Behavioral Brain Research, 48, 145-152.

HARRIS, R. J. (1985). A primer of multivariate statistics (2nd ed.). San Diego: Academic Press.

Hepler, D. J., Olton, D. S., Wenk, G. L., \& Coyle, J. T. (1985). Lesions in nucleus basalis magnocellularis and medial septal area of rats produce qualitatively similar memory impairments. Journal of Neuroscience, 5, 866-873.

Hutson, K. A., \& MASTERTON, R. B. (1986). The sensory contributions of a single vibrissa's cortical barrel. Journal of Neurophysiology, 56, $1196-1223$.

INGLIS, F. M., DAY, J. C., \& FiBIGER, H. C. (1994). Enhanced acetylcholine release in hippocampus and cortex during the anticipation and consumption of a palatable meal. Neuroscience, 62, 1049-1056.

INGLIS, F. M., \& FiBIGER, H. C. (1995). Increases in hippocampal and frontal cortical acetylcholine release associated with presentation of sensory stimuli. Neuroscience, 66, 81-86.

JaCOBS, S. E., \& JULiano, S. L. (1995). The impact of basal forebrain lesions on the ability of rats to perform a sensory discrimination task involving barrel cortex. Journal of Neuroscience, 15, 1099-1109.

Jenkins, W. M., Merzenich, M. M., Ochs, M. T., Allard, T., \& GuiCROBLES, E. (1990). Functional reorganization of primary somatosensory cortex in adult owl monkeys after behaviorally controlled tactile stimulation. Journal of Neurophysiology, 63, 82-104.
JiMÉNEZ-CAPDEVILLE, M. E., \& DYKES, R. W. (1993). Daily changes in the release of acetylcholine from rat primary somatosensory cortex, Brain Research, 625, 152-158.

Jiménez-Capdeville, M. E., Dykes, R. W., \& Myasnikov, A. A. (in press). Differential control of cortical activity by the basal forebrain in rats: A role for both cholinergic and inhibitory influences. Journal of Comparative Neurology.

Juliano, S. L., Ma, W., Bear, M. F., \& Eslin, D. (1990). Cholinergic manipulation alters stimulus-evoked metabolic activity in cat somatosensory cortex. Journal of Comparative Neurology, 297, 106-120.

Kametani, H., \& Kawamura, H. (1991). Circadian rhythm of cortical acetylcholine release as measured by in vivo microdialysis in freely moving rats. Neuroscience Letters, 132, 263-266.

KESNER, R. P. (1988). Reevaluation of the contribution of the basal forebrain cholinergic system to memory. Neurobiology of Aging, 9 , 609-616.

Knowlton, B. J., Wenk, G. L., Olton, D. S., \& Coyle, J. T. (1985). Basal forebrain lesions produce a dissociation of trial-dependent and trial-independent memory performance. Brain Research, 345, 315321.

KossuT, M. (1992). Plasticity of the barrel cortex neurons. Progress in Neurobiology, 39, 389-422.

Kurosawa, M., Sato, A., \& Sato, Y. (1992). Cutaneous mechanical stimulation increases extracellular acetylcholine release in cerebral cortex in anesthetized rats. Neurochemistry International, 21, 423427.

Maho, C., Hars, B., Edeline, J.-M., \& Hennevin, E. (1995). Conditioned changes in the basal forebrain: Relations with learninginduced cortical plasticity. Psychobiology, 23, 10-25.

MarkowsKa, A. L., Wenk, G. L., \& Olton, D. S. (1990). Nucleus basalis magnocellularis and memory: Differential effects of two neurotoxins. Behavioral \& Neural Biology, 54, 13-26.

MERZENICH, M. M., \& JeNKINS, W. M. (1993). Cortical representation of learned behaviors. In P. Anderson, $\emptyset$. Hvalby, O. Paulsen, \& B. Hökfelt (Eds.), Memory concepts: Basic and clinical aspects (pp. 437-454). Amsterdam: Elsevier.

Merzenich, M. M., Recanzone, G., Jenkins, W. M., Allard, T. T., \& Nudo, R. J. (1988). Cortical representational plasticity. In P. Rakic \& W. Singer (Eds.), Neurobiology of neocortex (pp. 41 67). New York: Wiley.

Metherate, R. C., \& ASHE, J. H. (1991). Basal forebrain stimulation modifies auditory cortex responsiveness by an action at muscarinic receptors. Brain Research, 559, 163-167.

Metherate, R. C., Tremblay, N., \& Dykes, R. W. (1988a). The effects of acetylcholine on response properties of cat somatosensory cortical neurons. Journal of Neurophysiology, 59, 1231-1252.

Metherate, R. C., Tremblay, N., \& Dykes, R. W. (1988b). Transient and prolonged effects of acetylcholine on responsiveness of cat somatosensory cortical neurons. Journal of Neurophysiology, 59, $1253-1276$.

Miyamoto, M., Kato, J., Narumi, S., \& Nagaoka, A. (1987). Characteristics of memory impairment following lesioning of the basal forebrain and medial septal nucleus in rats. Brain Research, 419 19-31.

Moore, H., Sarter, M., \& Bruno, J. P. (1992). Age-dependent modulation of in vivo cortical acetylcholine release by benzodiazepine receptor ligands. Brain Research, 596, 17-29.

Moore, H., Sarter, M., \& Bruno, J. P. (1993). Bidirectional modulation of stimulated cortical acetylcholine release by benzodiazepine receptor ligands. Brain Research, 637, 267-274.

MorRis, R. G. M., ANDERSON, E., LYNCH, G., \& BAUdRY, M. (1986). Selective impairment of learning and blockade of long-term potentiation by an N-methyl-D-aspartate receptor antagonist, AP5. $\mathrm{Na}$ ture, 319, 774-776.

MorRis, R. G. M., Davis, S., \& Butcher, S. P. (1989). The role of NMDA receptors in learning and memory. In J. C. Watkins \& G. L. Collingridge (Eds.), The NMDA receptor (pp. 137-152). New York: IRL.

Muir, J. L., Page, K. J., SiRinathsinghji, D. J., Robiins, T. W., \& EVERITT, B. J. (1993). Excitotoxic lesions of basal forebrain cholinergic neurons: Effects on learning, memory, and attention. Behavioral Brain Research, 57, 121-131. 
Nosten-Bertrand, M., Errington, M. L., Murphy, K. P. S. J., Tokugawa, Y., Barboni, E., Kozlova, E., Michalovich, D., Morris, R. G. M., Silver, J., Stewart, C. L., Bliss, T. V. P., \& Morris, R. J. (1996). Normal spatial learning despite regional inhibition of LTP in mice lacking Thy-1. Nature, 379, 826-829.

Olton, D. S. (1990). Dementia: Animal models of the cognitive impairments following damage to the basal forebrain cholinergic system. Brain Research Bulletin, 25, 499-502.

Olton, D. S., \& WENK, G. L. (1987). Dementia: Animal models of the cognitive impairment produced by degeneration of the basal forebrain cholinergic system. In H. Y. Meltzer (Ed.), Psychopharmacology: $A$ third generation of progress (pp. 941-953). New York: Raven.

Pang, K., Williams, M. J., Egeth, H., \& Olton, D. S. (1993). Nucleus basalis magnocellularis and attention: Effects of muscimol infusions. Behavioral Neuroscience, 107, 1031-1038.

PAXINOS, G., \& WATSON, C. (1986). The rat brain in stereotaxic coordinates (2nd ed.). New York: Academic Press.

PirCH, J. H. (1993). Basal forebrain and frontal cortex neuron responses during visual discrimination in the rat. Brain Research Bulletin, 31, 73-83.

Pirch, J. H., Rigdon, G., Rucker, H., \& Turco, K. (1990). Basal forebrain modulation of cortical cell activity during conditioning. In T. C. Napier, P. W. Kalivas, \& I. Hanin (Eds.), The basal forebrain: Anatomy to function (pp. 219-23!). New York: Plenum.

Pirch, J. H., TUrCo, K., \& Rucker, H. K. (1992). A role for acetylcholine in conditioning-related responses of rat frontal cortex neurons: Microiontophoretic evidence. Brain Research, 586, 19-26.

Potter, P. E., Meek, J. L., \& Neff, N. H. (1983). Acetylcholine and choline in neuronal tissue measured by HPLC with electrochemical detection. Journal of Neurochemistrv, 41, 188-194.

Rasmusson, D., \& Dykes, R. W. (1988). Long-term enhancement of evoked potentials in cat somatosensory cortex produced by coactivation of the basal forebrain and cutaneous receptors. Experimental Brain Research, 70, 276-286.

Rasmusson, D., \& Szerb, J. C. (1976). Acetylcholine release from visual and sensorimotor cortices of conditioned rabbits: The effects of sensory cuing and patterns of responding. Brain Research, 104, 243-259.

Recanzone, G., Jenkins, W. M., Hradek, G. T., \& Merzenich, M. (1992). Progressive improvement in discriminative abilities in adult owl monkeys performing a tactile frequency discrimination task. Journal of Neurophysiology, 87, 1015-1030.

Recanzonf, G., Schreiner, C., \& Merzenich, M. M. (1993). Plasticity in the frequency representation of primary auditory cortex following discrimination training in adult owl monkeys. Journal of Neuroscience, 13, 87-103.

Richardson, R. T., \& Delong, M. R. (1990). Context-dependent responses of primate nucleus basalis neurons in a go/no-go task. Journal of Neuroscience, 10. 2528-2540.

RichardSON, R. T., \& DeLong, M. R. (1991). Functional implications of tonic and phasic activity changes in nucleus basalis neurons. In R. Richardson (Ed.), Activation to acquisition: Functional aspects of the basal forebrain cholinergic system (pp. 135-166). Cambridge. MA: Birkhauser.

RiekKinen, M., RiekKinen, P., \& RiekKinen, P., JR., (1991). Comparison of quisqualic and ibotenic acid nucleus basalis magnocellularis lesions on water-maze and passive avoidance performance. Brain Research Bulletin, 27, 119-123.

Rigdon, G. C., \& Pirch, J. H. (1986). Nucleus basalis involvement in conditioned neuronal responses in the rat frontal cortex. Journal of Neuroscience, 6, 2535-2542.

Robbins, T. W., Everitt, B. J., Marston, H. M., Wilkinson, J., Jones, G. H., \& PAGE, K. J. (1989). Comparative effects of ibotenic acidand quisqualic acid-induced lesions of the substantia innominata on attentional function in the rat: Further implications for the role of the cholinergic neurons of the nucleus basalis in cognitive processes. Behavioral Brain Research. 35, 221-240.

Roberts, A. C., Robbins, T. W., Everitt, B. J., Jonfs, G. H., Sirkia, T. E., Wilkinson, J., \& Page, K. (1990). The effects of excitotoxic lesions of the basal forebrain on the acquisition, retention and serial reversal of visual discriminations in marmosets. Neuroscience, 34, 3!1-329.

ROBINSON, T. E., \& CAMP, D. M. (1991). The effects of four days of continuous striatal microdialysis on indices of dopamine and serotonin neurotransmission in rats. Journal of Neuroscience Methods, 40, $211-222$.

Roman, F. S., Chaillan, F. A., \& Soumireu-Mourat, B. (1993). Long-term potentiation in rat piriform cortex following discrimination learning. Brain Research, 601, 265-272.

Rosenblad, C., \& NiLSSON, O. G. (1993). Basal forebrain grafts in the rat neocortex restore in vivo acetylcholine release and respond to behavioral activation. Neuroscience, 55, 353-362.

Rye, D. B., Wainer, B. H., Mesulam, M. M., Mufson, E. J., \& Saper, C. B. (1984). Cortical projections arising from the basal forebrain: A study of cholinergic and noncholinergic components employing combined retrograde tracing and immunohistochemical localization of choline acetyltransferase. Neuroscience, 13, 627-643.

Sabol, K. E., Richards, J. B., \& Seiden, L. S. (1991). Fenfluramineinduced increases in extracellular hippocampal serotonin are progressively attenuated in vivo during a four-day fenfluramine regimen in rats. Brain Research, 571, 64-72.

Santucci, A. C., \& Haroutunian, V. (1989). Nucleus basalis lesions impair memory in rats on nonspatial and spatial discrimination tasks. Physiology \& Behavior, 45, 1025-1031.

SARTER, M. F., \& BRUNO, J. P. (1994). Cognitive functions of cortical ACh: Lessons from studies on trans-synaptic modulation of activated efflux. Trends in Neurosciences, 17, 217-221.

SAucier, D., \& CaIN, D. P. (1995). Spatial learning without NMDA receptor-dependent long-term potentiation. Nature, 378, 186-189.

Tremblay, N., WarRen, R. A., \& Dykes, R. W. (1990). Electrophysiological studies of acetylcholine and the role of the basal forebrain in the somatosensory cortex of the cat II. Cortical neurons excited by somatic stimuli. Journal of Neurophysiology, 64, 1212-1222.

UEKI, A., \& MiYoshi, K. (1989). Effects of cholinergic drugs on learning impairment in ventral globus pallidus-lesioned rats. Journal of Neurological Sciences, 90, 1-21.

Verdier, D., Maalouf, M., Myasnikov, A. A., \& Dykes, R. W. (1995). Long-term cholinergic enhancement: A form of LTP in the rat somatosensory cortex. Society for Neuroscience Abstracts, 21, 325.

Webster, H., Hanisch, U., Dykes, R. W., \& BieSOld, D. (1991). Basal forebrain lesions with or without reserpine injection innibit cortical reorganization in rat hindpaw primary somatosensory cortex following sciatic nerve section. Somatosensory \& Motor Research, $8,327-346$

WEINBERGER, N. M. (1993). Learning-induced changes of auditory receptive fields. Current Opinions in Neurobiology, 3, 570-577.

WEINBERGER, N. M. (1995). Dynamic regulation of receptive fields and maps in the adult sensory cortex. Annual Review of Neurology, 18, 129-158.

Weinberger, N. M., Ashe, J. H., Metherate, R., McKenna, T. M., DiAmOND, D. M., \& BAKIN, J. S. (1990). Retuning auditory cortex by learning: A preliminary model of receptive field plasticity. Concepts in Neuroscience, 1, 91-131.

Weingerger, N. M., \& Diamond, D. M. (1987). Physiological plasticity in auditory cortex: Rapid induction by learning. Progress in Neurobiology, 29, 1-55.

Wilson, F. A. W., \& Rolls, E. T. (1990). Neuronal responses related to reinforcement in the primate basal forebrain. Brain Research, 509. 213-231.

WINER, B. J. (1971). Statistical principles in experimental design. New York: McGraw-Hill.

Wozniak, D. F., Stewart, G. R., Finger, S., Olney, J. W., \& CozZARI, C. (1989). Basal forebrain lesions impair tactile discrimination and working memory. Neurobiology of Aging, 10, 173-179.

(Manuscript received September 30, 1996; revision accepted for publication December 4, 1996.) 